\title{
North Pacific Decadal Variability in the Community Climate System Model Version 2
}

\author{
Young-Oh Kwon and Clara Deser \\ Climate and Global Dynamics Division, National Center for Atmospheric Research, Boulder, Colorado
}

(Manuscript received 4 May 2006, in final form 14 September 2006)

\begin{abstract}
North Pacific decadal oceanic and atmospheric variability is examined from a 650-yr control integration of the Community Climate System Model version 2. The dominant pattern of winter sea surface temperature (SST) variability is similar to the observed "Pacific decadal oscillation," with maximum amplitude along the Kuroshio Extension. SST anomalies in this region exhibit significant spectral peaks at approximately 16 and $40 \mathrm{yr}$. Lateral geostrophic heat flux divergence, caused by a meridional shift of the Kuroshio Extension forced by basin-scale wind stress curl anomalies 3-5 yr earlier, is responsible for the decadal SST variability; local surface heat flux and Ekman heat flux divergence act as a damping and positive feedback, respectively. A simple linear Rossby wave model is invoked to explicitly demonstrate the link between the wind stress curl forcing and decadal variability in the Kuroshio Extension. The Rossby wave model not only successfully reproduces the two decadal spectral peaks, but also illustrates that only the low-frequency ( $>10$-yr period) portion of the approximately white noise wind stress curl forcing is relevant. This model also demonstrates that the weak and insignificant decadal spectral peaks in the wind stress curl forcing are necessary for producing the corresponding strong and significant oceanic peaks in the Kuroshio Extension. The wind stress curl response to decadal SST anomalies in the Kuroshio Extension is similar in structure but opposite in sign and somewhat weaker than the wind stress curl forcing pattern. These results suggest that the simulated North Pacific decadal variability owes its existence to two-way ocean-atmosphere coupling.
\end{abstract}

\section{Introduction}

Significant low-frequency variability of sea surface temperature (SST) anomalies at decadal and longer time scales has been observed in the North Pacific (e.g., Trenberth and Hurrell 1994; Nakamura et al. 1997) and has been termed the "Pacific decadal oscillation" (PDO) (Mantua et al. 1997). SST anomalies associated with the PDO exhibit a basinwide horseshoelike spatial pattern with one sign in the central and western North Pacific surrounded by the opposite sign to the north, east, and south (Mantua et al. 1997). The maximum anomalies are found in the central North Pacific and a weaker secondary maximum is located along the Kuroshio Extension. Several studies have suggested that these two centers of action may be distinguished based on their spectral characteristics and relative dependence on the Tropics. The center of action in the central

Corresponding author address: Young-Oh Kwon, Physical Oceanography Department, Woods Hole Oceanographic Institution, Clark 320A, MS 21, Woods Hole, MA 02543.

E-mail: yokwon@whoi.edu
North Pacific has relatively more power in the interannual frequency band with a strong connection to tropical ENSO variability, while that along the Kuroshio Extension has more power at decadal and longer time scales with a weaker connection to the Tropics (Deser and Blackmon 1995; Nakamura et al. 1997; Schneider and Cornuelle 2005).

Seager et al. (2001) examined in detail the differences in the evolution of SST anomalies at these two centers of action as a response to changes in atmospheric forcing associated with the 1976/77 PDO transition, using both observations and a numerical ocean model hindcast. After 1976 the winter Aleutian low deepened and moved southeast of its previous position, placing the North Pacific under anomalous cyclonic flow. In the central North Pacific stronger westerlies cooled the ocean by increased equatorward Ekman transport. This Ekman response was fast and local, and cooled the SST beginning in 1977. On the other hand, negative SST anomalies emerged near the Kuroshio Extension in the early 1980s, in association with a southward displacement of the boundary between the subpolar and subtropical gyres caused by a southward

DOI: $10.1175 /$ JCLI4103.1

(C) 2007 American Meteorological Society 
shift in the zero wind stress curl line 4 years earlier. The delay time was attributed to the time scale for the gyre adjustment via first-mode baroclinic Rossby waves. The SST cooling in the Kuroshio Extension was shown to be damped by surface heat fluxes, implying an oceanic origin for the SST anomalies in the Kuroshio Extension. Many other studies also presented consistent results (Miller et al. 1994; Deser et al. 1999; Xie et al. 2000; Pierce et al. 2001; Schneider et al. 2002; Schneider and Cornuelle 2005).

Although these hindcast modeling and observational studies provided an understanding of the ocean's role in low-frequency SST variability in response to atmospheric circulation changes, they were limited with regard to the role of ocean to atmosphere feedback. Therefore, fully coupled general circulation models or conceptual models were employed to explore the physical mechanisms of PDO-like decadal variability. In a seminal study, Latif and Barnett (1994) analyzed a 70$\mathrm{yr}$ integration of a fully coupled general circulation model, ECHO1; their findings were updated with a 125$\mathrm{yr}$ integration of the same model in Latif and Barnett (1996). They suggested that the decadal variability in the North Pacific can be attributed to a cycle involving unstable ocean-atmosphere interaction between the subtropical ocean gyre circulation and the Aleutian low pressure system. When, for instance, the Aleutian low is anomalously deep, the subtropical ocean gyre is spun up with a delay of about 5 years due to geostrophic adjustment via the first baroclinic-mode Rossby wave. They suggested that the delay time scale is determined to first order by the basin crossing time of the Rossby wave, but the role of advection by the mean current is not negligible. An anomalously strong subtropical gyre transports more warm water into the Kuroshio Extension, leading to positive SST anomalies in the western and central North Pacific. The atmospheric response to the positive SST anomalies involves a weakened Aleutian low, which initiates the opposite phase of their 20 -yr oscillation. The associated surface heat flux reinforces the initial SST anomalies so that the ocean and atmosphere act as a positive feedback system.

There are a few steps in their proposed mechanism that may be inconsistent with or cannot be resolved by the observations and realistic hindcast simulations. In particular Seager et al. (2001) found that a southward shift, rather than an in situ strengthening, of the atmospheric circulation and subsequently the ocean gyre circulation is responsible for the SST anomalies in the Kuroshio Extension associated with the 1976/77 PDO transition. This is similar to the finding of Marshall et al. (2001) for the North Atlantic. In addition Seager et al. (2001) found that the surface heat flux damps the SST anomalies in the Kuroshio Extension both in observations and the ocean model hindcast (see also Tanimoto et al. 2003; Kelly 2004), opposite to the results of Latif and Barnett (1994). Finally, Latif and Barnett used a stand-alone atmospheric general circulation model experiment to show that SST anomalies from the coupled integration can force the atmospheric circulation to shift to the opposite phase, leading to an oscillatory mode. However, the magnitude of their atmospheric response was much larger than that found in other studies and even the sign of the atmospheric response was not consistent with some of the previous studies (Kushnir et al. 2002).

As a follow-up of Latif and Barnett (1994), Pierce et al. (2001) investigated decadal variability in the North Pacific from a 137-yr integration of ECHO2 and a 270yr integration of the Climate System Model version 1 (CSM1) [the predecessor of the Community Climate System Model version 2 (CCSM2)]. They concluded that ocean dynamics within the North Pacific are necessary for the existence of a statistically significant decadal spectral peak in SST anomalies along the Kuroshio Extension. They went on to test the role of "spatial resonance" (Saravanan and McWilliams 1998) between stochastic atmospheric forcing and oceanic dynamic response using the ocean component model of $\mathrm{ECHO} 2$ forced by time-permuted $\mathrm{ECHO} 2$ atmospheric variables. They found that the decadal spectral peak is not reproduced when the ocean model is forced by a stochastic atmosphere, a result that led them to conclude that the decadal spectral peak is maintained by a midlatitude atmosphere-ocean coupled mode such as that proposed by Latif and Barnett (1994). However, unlike Latif and Barnett but similar to Seager et al. (2001), they found that meridional shifts of the boundary between the subpolar and subtropical gyres are responsible for the decadal SST anomalies in the Kuroshio Extension and that the surface heat flux damps the SST anomalies in the Kuroshio Extension. They also found a more reasonable magnitude for the atmospheric response to the coupled model's SST anomalies than Latif and Barnett (1994). Their test for the role of spatial resonance was, however, not entirely conclusive as briefly discussed in Schneider et al. (2002) because they prescribed stochastic wind stress curl and surface heat flux forcing even in the Kuroshio Extension where the SST anomalies are not forced but actually damped by the surface heat flux in their coupled model.

Schneider et al. (2002) examined North Pacific decadal variability from a 147-yr integration of ECHO2, the same integration used by Pierce et al. (2001), but 
arrived at a rather different conclusion regarding the decadal time-scale selection. They investigated the role of white noise wind stress curl forcing using a strategy similar to that of Pierce et al. (2001), but used a linear Rossby wave model instead of an ocean general circulation model. Consistent with Pierce et al., the oceanic decadal spectral peak is not reproduced when the Rossby wave model is forced by white noise wind stress curl anomalies. Next, Schneider et al. (2002) incorporated an ocean to atmosphere feedback term in the Rossby wave model to test the existence of a midlatitude atmosphere-ocean coupled oscillation. The modified model was integrated with both positive and negative feedback cases, but neither reproduced the decadal peak. They therefore concluded that the results of $\mathrm{ECHO} 2$ are inconsistent with a midlatitude atmosphere-ocean coupled oscillation.

Neelin and Weng (1999) examined the role of ocean to atmosphere feedback in midlatitude decadal variability using a conceptual model. They considered a linearized perturbation system with the ocean represented by quasigeostrophic shallow-water dynamics and a surface mixed layer, and the atmosphere represented by stochastic wind stress and heat flux forcing comprising a noise component that depends on SST as well as an additive component that is independent of SST. Coupling, which allows a weak and irregular atmospheric response to decadal SST anomalies, is represented by the SST-dependent noise component. Without coupling, their model produces a weak decadal oceanic peak due to spatial resonance (Jin 1997; Saravanan and McWilliams 1998) when a zonal wavenumber-one pattern is specified for the atmospheric forcing. With coupling, the decadal peak originally introduced by spatial resonance becomes stronger and more distinctive. Thus, a weak and irregular ocean to atmosphere feedback is sufficient to maintain a coupled mode of decadal variability.

In this study, we examine decadal variability in the North Pacific from a 650-yr integration of present-day climate using the CCSM2 developed at the National Center for Atmospheric Research (NCAR). CCSM2 exhibits decadal SST variability similar to the observed PDO. The purpose of this study is to take advantage of this long CCSM2 integration to examine unresolved issues regarding North Pacific decadal variability, including the robustness of the atmospheric response to SST anomalies in the Kuroshio Extension and its role in maintaining decadal variability. We perform a careful heat budget analysis in the Kuroshio Extension to understand the roles of surface heat flux, Ekman heat flux divergence, and geostrophic heat flux divergence in the decadal SST variability. We employ a linear Rossby wave model to demonstrate the importance of the atmospheric response for the decadal variability and use three independent approaches to examine the robustness of the atmospheric response: lag-regression analysis using CCSM2 output, a stand-alone atmospheric general circulation model experiment, and a coupled atmospheric general circulation-ocean mixed layer model experiment. With this long CCSM2 integration, we are able to perform a statistically robust analysis of the mechanisms responsible for the PDO-like decadal variability. Section 2 describes the model and analysis methods. Results are presented in section 3, and discussed in section 4. Conclusions are presented in section 5 .

\section{Model description and analysis methods}

The Community Climate System Model version 2 consists of atmosphere, ocean, sea ice, and land component models mutually linked by means of a coupler (Kiehl and Gent 2004). The atmospheric component of CCSM2 is the Community Atmospheric Model version 2.0 (CAM2.0), which has T42 horizontal resolution and 26 vertical levels. The ocean component uses the Parallel Ocean Program (POP) (Smith et al. 1992), which has a horizontal resolution of $1.125^{\circ}$ in the zonal direction and a meridional resolution of $0.27^{\circ}$ at the equator gradually increasing to a maximum of $\sim 0.6^{\circ}$ at about $40^{\circ} \mathrm{N}$. There are 40 levels in the vertical, whose thickness monotonically increases from $10 \mathrm{~m}$ near the surface to $250 \mathrm{~m}$ in the deep ocean below $1500 \mathrm{~m}$. The land and sea ice components of the CCSM2 are the Community Land Model version 2.0 (CLM2.0) and the Community Sea Ice Model version 4 (CSIM4), which have the same horizontal resolution as the atmospheric and ocean component models, respectively. The reader is referred to Kiehl and Gent (2004) for further description of CCSM2.

The control integration is intended to simulate the "present day" climate, with greenhouse gases concentrations set to their 1990 levels. The ocean component was initialized using January mean climatological temperature and salinity fields from Levitus et al. (1994) and from Steele et al. (2001) in the Arctic Ocean. The atmosphere, land, and sea ice components were initialized using realistic January fields obtained from standalone integrations of these three component models. The CCSM2 control integration was run for 350 years without any flux adjustments, whereupon three minor changes were made to the code and the integration was restarted to run out to year 999, again without any flux adjustments. Kiehl and Gent (2004) document this control integration in more detail, including the compari- 


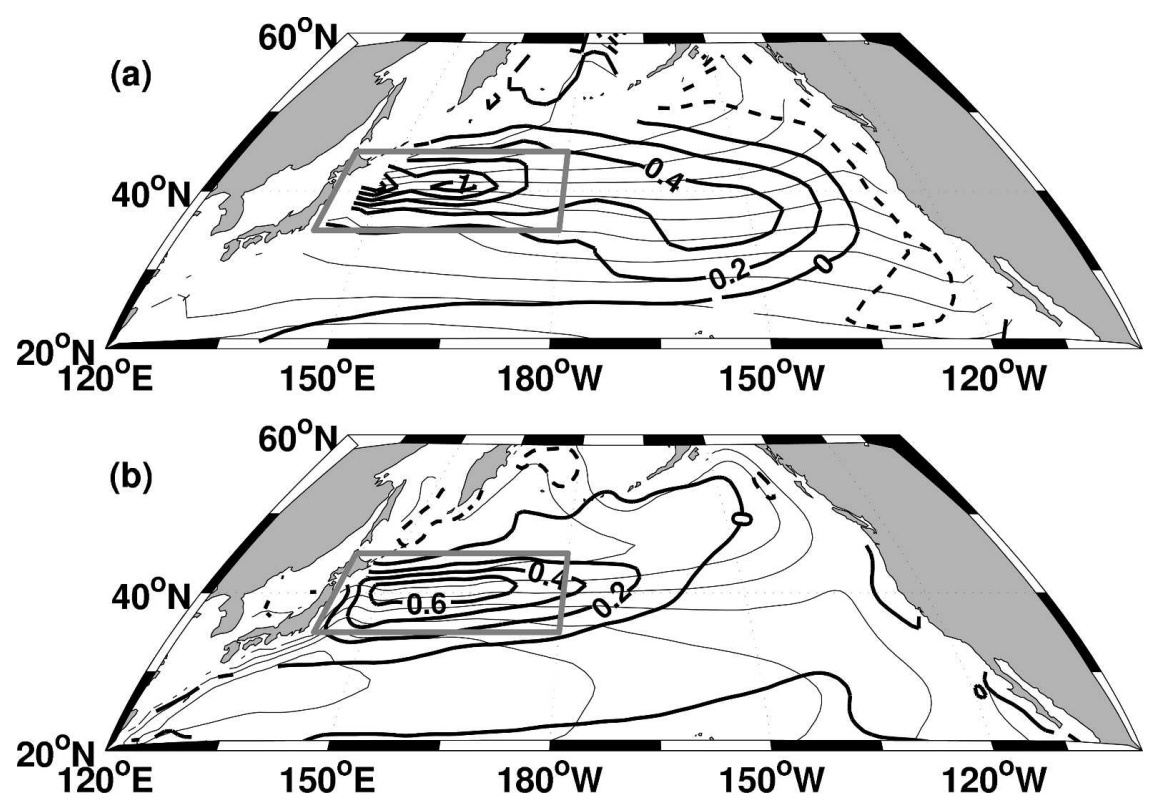

FIG. 1. Leading EOF patterns of winter (DJFM) (a) SST anomalies and (b) subsurface ocean temperature anomalies at $500-\mathrm{m}$ depth in the North Pacific $\left(20^{\circ}-60^{\circ} \mathrm{N}\right)$ from CCSM2. Amplitudes correspond to a one standard deviation change of the corresponding principal component time series. Contour interval is $0.2^{\circ} \mathrm{C}$, with negative contours dashed. Thin contours denote the climatological winter (DJFM) mean SST and 500-m temperature fields. Contour interval for the mean fields is $2^{\circ} \mathrm{C}$. Gray solid boxes indicate the averaging region for the SST and 500-m temperature index time series, referred to as the Kuroshio Extension index.

sons of the mean climatologies with observations and the impacts of the changes at year 350 . This study analyzes results for the last 650 years of the control integration (years 350-999).

Standard methods of analysis, including empirical orthogonal functions (EOFs), lag correlation and regression, and spectral analysis are used. The mean annual cycle is removed by subtracting the 650-yr long-term monthly means from each month. EOFs are computed from the covariance matrix of input time series, and are displayed as regressions on the corresponding normalized principal component (PC) time series, so that the amplitude of the EOFs corresponds to the one standard deviation changes of the PC. All time series are detrended before calculating correlation, regression, or power spectrum, although the results presented in this study were not sensitive to detrending. The statistical significance of the correlation or regression coefficients is assessed according to a two-sided Student's $t$ test using an effective temporal degree of freedom taking into account serial autocorrelation. Statistical significances are indicated at the $99 \%$ confidence level for all correlation and regression plots. The statistical significance for the power spectrum is indicated at the $95 \%$ and $99 \%$ confidence levels with respect to a red noise null hypothesis based upon a first-order autoregressive process with the autocorrelation of the corresponding time series.

\section{Results}

\section{a. Decadal variability of SST and subsurface temperature in the North Pacific}

The leading EOF of winter [December-March (DJFM)] SST anomalies from CCSM2 exhibits anomalies of one sign in the western and central North Pacific centered along the Kuroshio Extension near $40^{\circ} \mathrm{N}$, surrounded by anomalies of the opposite sign along the west coast of North America (Fig. 1a). This mode accounts for $20 \%$ of the variance of winter SST anomalies and is nearly identical to the leading EOF of monthly SST anomalies (not shown). The primary center of action along the Kuroshio Extension coincides with the maximum meridional gradient of the climatological mean SST. The simulated EOF pattern resembles observations, although the latter has its primary maximum in the central North Pacific with a weaker secondary maximum along the Kuroshio Extension (Deser and Blackmon 1995; Mantua et al. 1997; Nakamura et al. 1997; Schneider and Cornuelle 2005). The leading EOF 
of subsurface temperature anomalies at 500-m depth, which lies within the main thermocline, also exhibits a maximum in the western North Pacific along the Kuroshio Extension near $40^{\circ} \mathrm{N}$, collocated with the maximum meridional gradient of the climatological mean 500-m temperature field (Fig. 1b). Note that unlike SST, 500-m temperature anomalies associated with EOF 1 are very weak in the central and eastern North Pacific, similar to observations (Miller et al. 1998; Deser et al. 1999).

The time series of winter SST anomalies averaged over the Kuroshio Extension $\left(35^{\circ}-45^{\circ} \mathrm{N}, 140^{\circ} \mathrm{E}-180^{\circ}\right.$; the region outlined by the gray box in Fig. 1a), the SST Kuroshio Extension index (SSTKEI), exhibits pronounced decadal variability that is apparent even in unsmoothed time series (shaded bars in Fig. 2a). The SSTKEI is highly correlated $(r=0.88)$ with the leading SST PC time series. The power spectrum of the SSTKEI exhibits two low-frequency peaks: one around the 15-20-yr period (hereafter referred to as the 16-yr peak) and the other around the 38-45-yr period (hereafter 40-yr peak). These 16- and 40-yr spectral peaks are statistically significant at $99 \%$ and $95 \%$, respectively, with respect to a first-order autoregressive model. Observed winter SST anomalies in the Kuroshio Extension in the twentieth century show a weak spectral peak at 20-30-yr periods (Pierce et al. 2001).

The time series of 500-m temperature anomalies averaged over the Kuroshio Extension index region is highly correlated ( $r=0.66$, significant at the $99 \%$ confidence level) with the SSTKEI (solid line in Fig. 2a), and exhibits similar spectral peaks at 16 and $40 \mathrm{yr}$ (Fig. 2c). The enhanced power at periods longer than about $100 \mathrm{yr}$ is due to a slight decreasing trend in the first $200 \mathrm{yr}$ of the time series as the deep ocean comes into equilibrium (Kiehl and Gent 2004). The 500-m temperature time series has almost negligible power in the frequency range higher than 0.1 cycles per year (cpy), which makes the time series appear smoother than the SSTKEI.

Lag regressions of 10-yr low-pass-filtered SST and 500-m temperature anomalies upon the SSTKEI show the evolution of the decadal temperature anomalies (Fig. 3). From lag -4 to $+2 \mathrm{yr}$, positive anomalies expand eastward from Japan to occupy almost the half of the basin. At lag $+4 \mathrm{yr}$, a negative anomaly develops

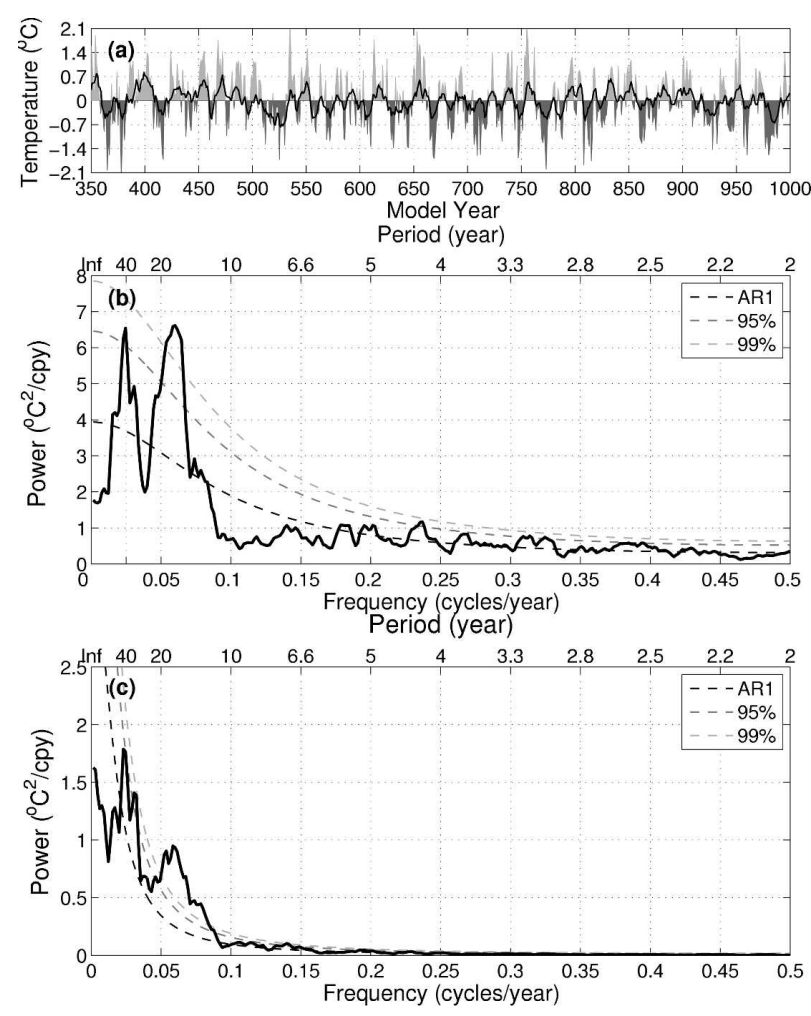

FIG. 2. (a) Winter (DJFM) SST anomalies (shaded bars) and 500-m temperature (solid curve) Kuroshio Extension index (35 $45^{\circ} \mathrm{N}, 140^{\circ} \mathrm{E}-180^{\circ}$ ). Power spectrum of the (b) SST and (c) $500-\mathrm{m}$ temperature index time series. The best-fit first-order autoregressive model (AR1) spectrum and associated $95 \%$ and $99 \%$ significant levels are plotted with dashed lines based on the 1-yr lag autocorrelations of the index time series.

off Japan and evolves in a similar fashion to the positive anomalies. The positive SST anomalies dissipate rapidly from lag +2 to $+4 \mathrm{yr}$, whereas those at 500-m depth persist through lag $+14 \mathrm{yr}$ as they continue to propagate eastward, eventually dissipating in the Gulf of Alaska.

\section{b. Local diagnosis of the decadal variability in the Kuroshio Extension}

As a first step to understand the processes responsible for driving the decadal variability of ocean temperature anomalies in the Kuroshio Extension, we examine the local heat budget for the upper $200 \mathrm{~m}$ in the following form:

$$
\frac{\partial T}{\partial t}=\underbrace{\frac{1}{\rho_{0} C_{p} H} Q_{\mathrm{net}}}_{\text {(i) }}-\underbrace{\left(u_{\mathrm{Ek}} \frac{\partial T}{\partial x}+v_{\mathrm{Ek}} \frac{\partial T}{\partial y}\right)}_{\text {(ii) }}-\underbrace{\left(u_{\mathrm{geo}} \frac{\partial T}{\partial x}+v_{\mathrm{geo}} \frac{\partial T}{\partial y}\right)}_{\text {(iii) }}-\underbrace{w \frac{\partial T}{\partial z}}_{\text {(iv) }}+\text { residual, }
$$




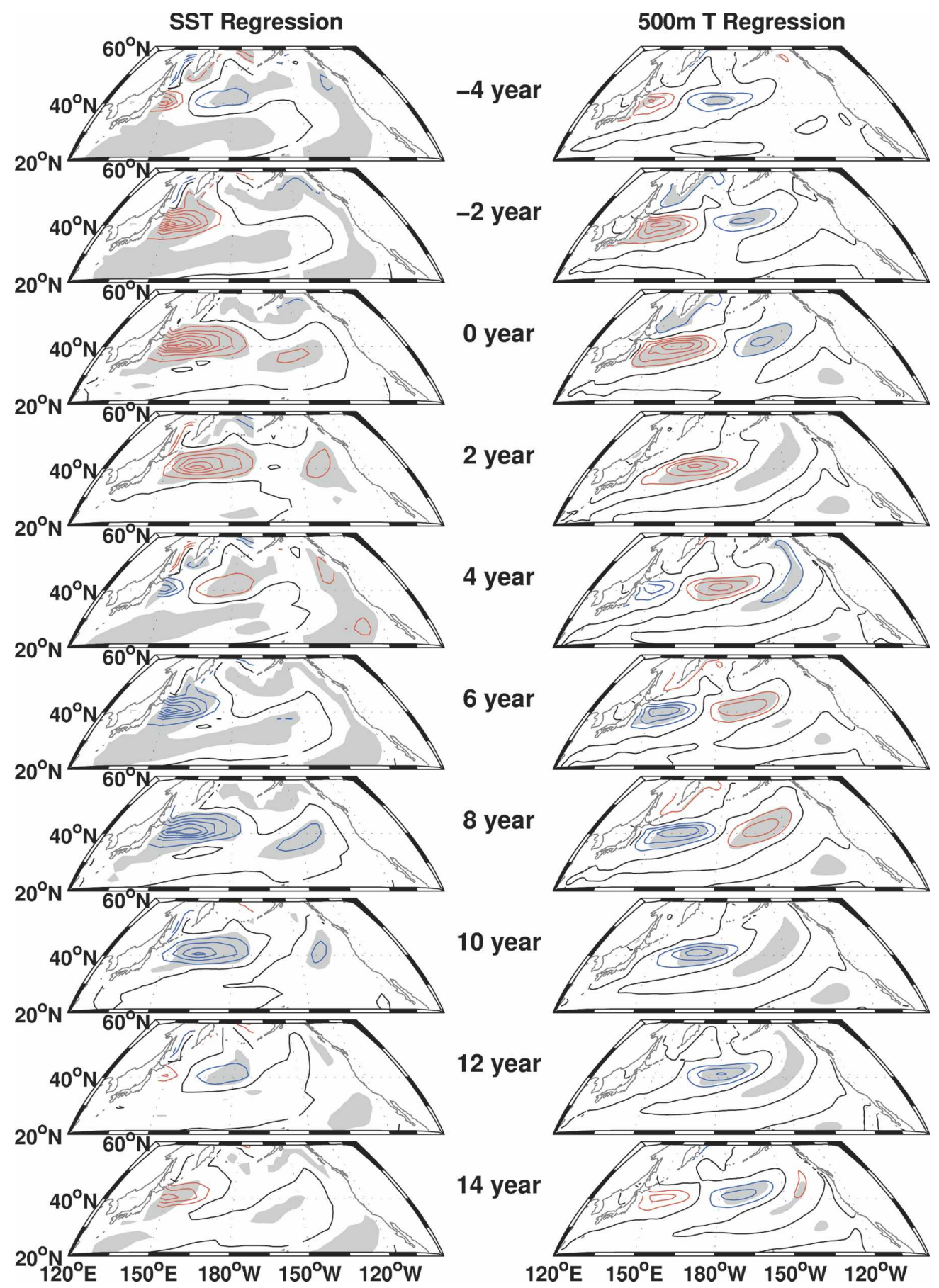

FIG. 3. Lag regressions of DJFM (left) SST and (right) 500-m temperature on the SSTKEI. Lags are noted in the center column: positive (negative) lag indicating the index time series is leading (lagging) the temperature field. Positive (negative) regression coefficients are contoured with red (blue) lines. Zero contours are plotted with black lines. Contour interval is $0.3^{\circ} \mathrm{C}^{\circ} \mathrm{C}^{-1}$, and gray shadings indicate regression values significant at $99 \%$. All variables are low-pass filtered to retain periods longer than $10 \mathrm{yr}$.

where $T$ is the ocean temperature, $Q_{\text {net }}$ is the net airsea surface heat flux, $H$ is the upper-ocean thickness $(=200 \mathrm{~m}), u_{\mathrm{Ek}}\left(v_{\mathrm{Ek}}\right)$ is the zonal (meridional) Ekman velocity, $u_{\text {geo }}\left(v_{\text {geo }}\right)$ is the zonal (meridional) geo- strophic velocity, and $w$ is the total vertical velocity. All the terms not explicitly listed, including diffusion, make up the residual. The three leading terms on the righthand side of Eq. (1) [i.e., (i) the net surface heat flux, 


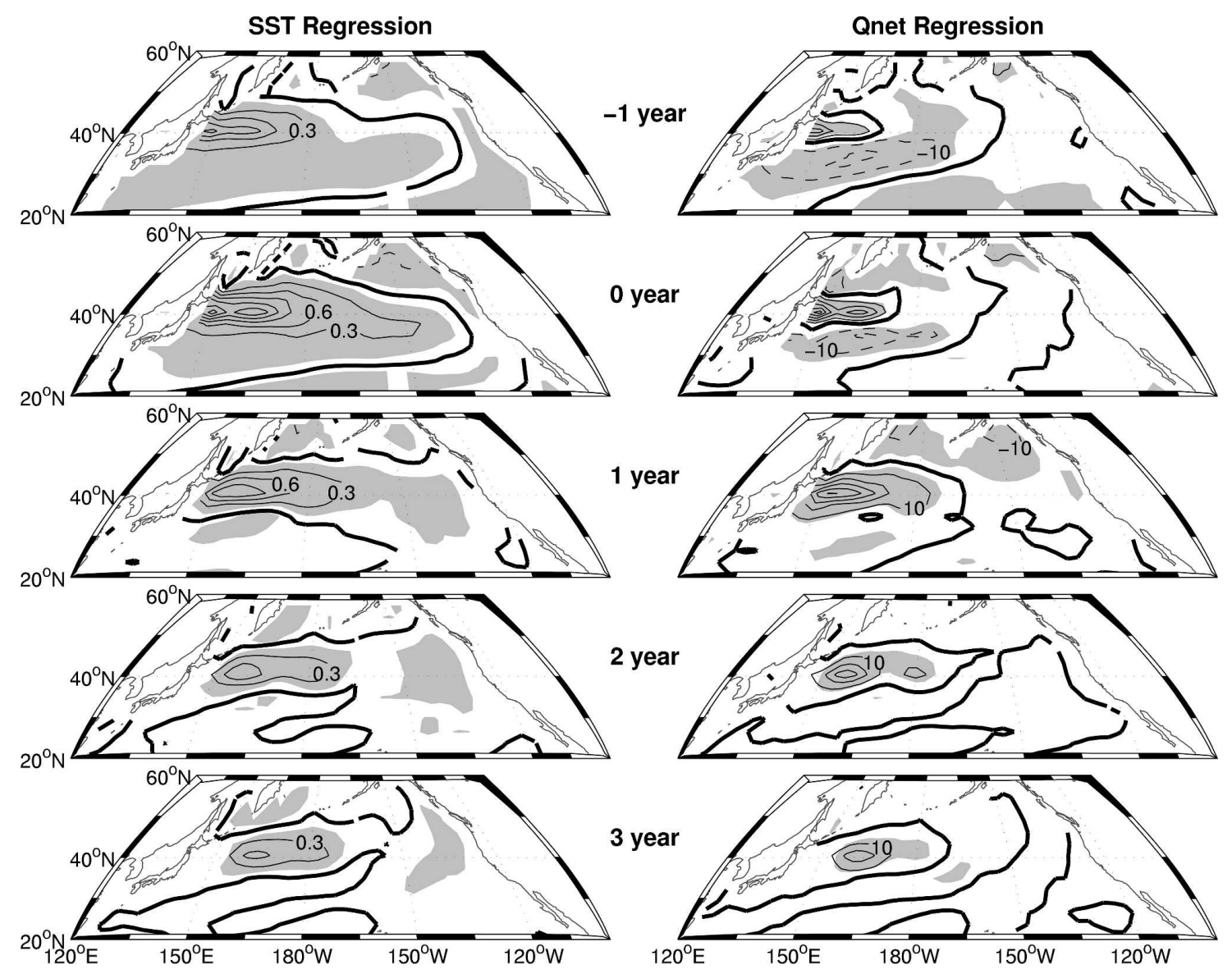

FIG. 4. Lag regressions of DJFM (left) SST and (right) net surface heat flux on the SSTKEI. No filtering is applied. Lags are noted in the center column: positive lag indicates the index time series is leading and vice versa. Positive regression coefficients for the net surface heat flux denote heat transferred from ocean to atmosphere. Negative values are contoured with dashed lines. Contour interval is $0.3^{\circ} \mathrm{C}^{\circ} \mathrm{C}^{-1}$ and $10 \mathrm{~W} \mathrm{~m}^{-2}{ }^{\circ} \mathrm{C}^{-1}$, respectively. Shadings indicate regressions significant at $99 \%$.

(ii) the horizontal Ekman heat flux divergence, and (iii) the horizontal geostrophic heat flux divergence] dominate the upper-ocean heat budget in the Kuroshio Extension and are examined in detail below.

First, the role of local net surface heat flux $\left(Q_{\text {net }}\right)$ is examined by means of lag regressions of the winter $Q_{\text {net }}$ anomalies on the winter SSTKEI (right column in Fig. 4): note that positive (negative) $Q_{\text {net }}$ regressions denote cooling (heating) of the sea surface. To illustrate the relation with the SST anomalies, the corresponding lag regressions of the winter SST anomalies on the SSTKEI are also shown (left column in Fig. 4). Note that the regressions are based on unfiltered data unlike those shown in Fig. 3. Here $Q_{\text {net }}$ regressions at -1 and $0 \mathrm{yr}$ lags illustrate the mixture of $Q_{\text {net }}$ forcing and response to the SST anomalies. The positive $Q_{\text {net }}$ anomalies over the upstream portion of the Kuroshio Extension occur in response to the local maximum of the warm SST anomalies, transferring excessive heat from ocean to the atmosphere. At lags -1 and $0 \mathrm{yr}$, negative $Q_{\text {net }}$ anomalies directly south and east of the Kuroshio Extension drive positive SST anomalies, thereby broadening the warm SST anomalies southward and eastward. The $Q_{\text {net }}$ also contributes to forcing the negative SST anomalies in the eastern half of the basin at lags -1 and 0 . The local response of $Q_{\text {net }}$ to SST along the Kuroshio Extension is clearly evident at all lags, and the regressions at lags 2 and $3 \mathrm{yr}$ even show the $Q_{\text {net }}$ anomalies propagating eastward in response to the propagating warm SST anomalies. The strength of net surface heat flux response to the SST anomalies implied from the regressions at 1 -yr lag is $39 \mathrm{~W} \mathrm{~m}^{-2}{ }^{\circ} \mathrm{C}^{-1}$ averaged over the Kuroshio Extension. Similar values $\left(40-50 \mathrm{~W} \mathrm{~m}^{-2}\right.$ ${ }^{\circ} \mathrm{C}^{-1}$ ) have been estimated from the observations (Frankignoul and Kestenare 2002; Park et al. 2005).

The time series of winter $Q_{\text {net }}$ averaged over the Kuroshio Extension illustrates the close correspondence with the SSTKEI: their maximum lagged corre- 

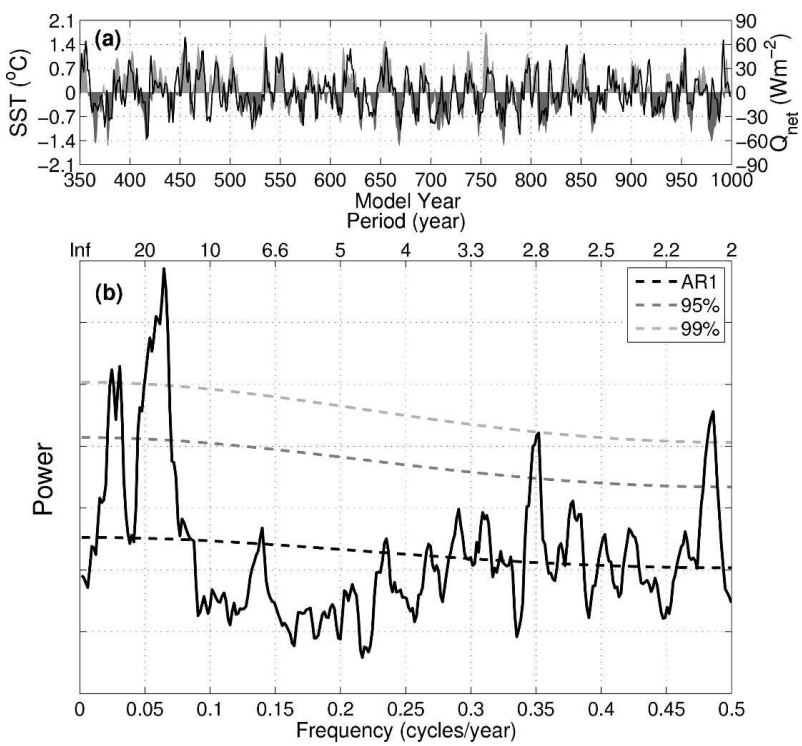

FIG. 5. (a) DJFM net surface heat flux anomalies in the Kuroshio Extension $\left(35^{\circ}-45^{\circ} \mathrm{N}, 140^{\circ}-170^{\circ} \mathrm{E}\right)$ (solid curve) and SSTKEI (shaded bars). Positive heat flux anomalies denote heat transferred from ocean to atmosphere. Note that 1-2-1 smoothing has been applied to both time series just for the visualization. (b) Power spectrum of the net surface heat flux anomaly time series. The best-fit first-order autoregressive model (AR1) spectrum and associated $95 \%$ and $99 \%$ significant levels are plotted with dashed lines based on the 1-yr lag autocorrelations of the index time series.

lation ( $r=0.58$ ) occurs when the SSTKEI leads $Q_{\text {net }}$ by 1 yr (Fig. 5a). The power spectrum of the $Q_{\text {net }}$ time series exhibits two low-frequency peaks corresponding to the 16- and 40-yr peaks in the SSTKEI (Fig. 5b). Both peaks are significant at the $99 \%$ confidence level. As discussed in Czaja and Frankignoul (2002), the 1-yr lag should not be interpreted as a delay time in the atmospheric response. The simultaneous correlation or regression can be understood as a mixture of $Q_{\text {net }}$ forcing and response to the SST anomalies. Therefore, at zero lag the positive correlation due to $Q_{\text {net }}$ responding to SST anomalies partially offsets the negative correlation due to $Q_{\text {net }}$ forcing SST. On the other hand, the correlation at 1-yr lag fully reflects the $Q_{\text {net }}$ response, free from interference of the $Q_{\text {net }}$ forcing because of short atmospheric persistence.

The simultaneous regression pattern of the total winter Ekman heat flux divergence onto the SSTKEI exhibits zonally elongated negative anomalies in the western half of the basin located slightly south of the maximum positive SST anomalies (Fig. 6a). Note that negative regression coefficients indicate heat convergence, which implies SST warming. Decomposition of the Ekman heat flux divergence into $\overline{\mathbf{V}_{\mathrm{Ek}}} \cdot \nabla S S T^{\prime}$, $\mathbf{V}_{\mathrm{Ek}}^{\prime} \cdot \nabla \overline{\mathrm{SST}}$, and $\mathbf{V}_{\mathrm{Ek}}^{\prime} \cdot \nabla S S T^{\prime}$, where the overbar denotes the climatological winter mean and the prime denotes anomalies from the climatological mean, shows that the regression of total Ekman heat flux divergence is dominated by the contribution from the product of the time mean Ekman transport and the gradient of the anomalous SST (Fig. 6). This implies that the Ekman heat flux divergence acts to enhance the preexisting SST anomalies preferentially in the southern half, rather than as a direct forcing of the SST anomalies.

Finally, the role of the horizontal geostrophic heat flux divergence is examined. Lag correlation between the SSTKEI and the geostrophic heat flux divergence averaged over the Kuroshio Extension exhibits maximum correlation $(r=-0.76)$ when the geostrophic heat flux divergence leads SSTKEI by $0-1$ yr (Fig. 7a). The negative correlation implies that positive SST anomalies are induced by anomalous heat flux convergence. Furthermore, lag correlation between the sur-
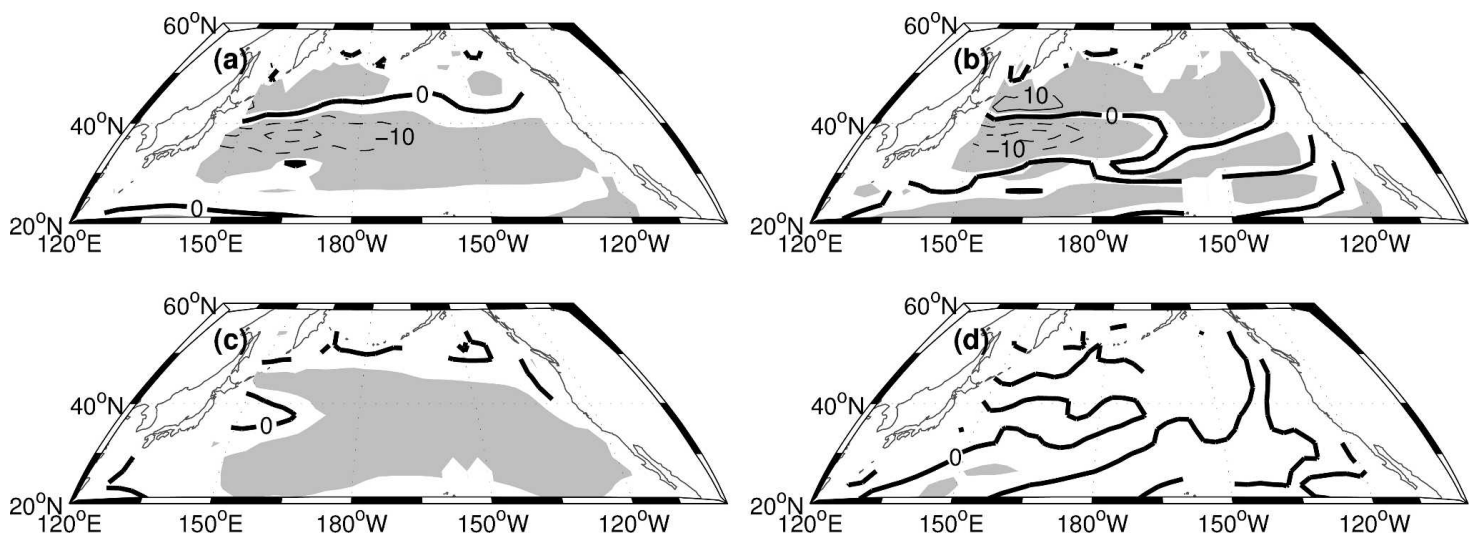

FIG. 6. Simultaneous regression coefficients of DJFM Ekman heat flux divergence on the SSTKEI. (a) Total $\left(\mathbf{V}_{\mathrm{Ek}} \cdot \nabla S S T\right)$, (b) $\overline{\mathbf{V}_{\mathrm{Ek}}} \cdot \nabla S S T^{\prime}$, (c) $\mathbf{V}_{\mathrm{Ek}}^{\prime} \cdot \nabla \overline{S S T}$, and (d) $\mathbf{V}_{\mathrm{Ek}}^{\prime} \cdot \nabla S S T^{\prime}$. Positive (negative) values indicate heat divergence (convergence). Negative values are contoured with dashed lines. Contour interval is $10 \mathrm{~W} \mathrm{~m}^{-2}{ }^{\circ} \mathrm{C}^{-1}$, and the shading indicates regression coefficients significant at $99 \%$. All variables are low-pass filtered to retain periods longer than $10 \mathrm{yr}$. 

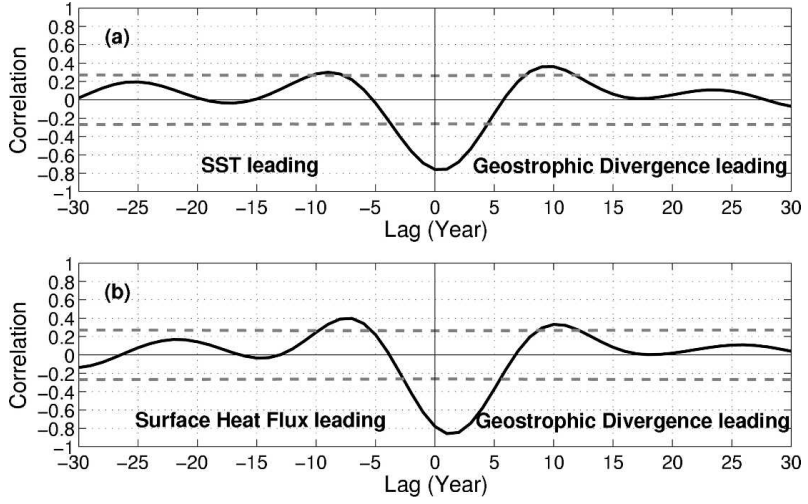

FIG. 7. Lag correlations of the winter (DJFM) horizontal geostrophic heat flux divergence in the upper $200 \mathrm{~m}$ with (a) SST and (b) net surface heat flux. All three variables are averaged over the Kuroshio Extension $\left(35^{\circ}-45^{\circ} \mathrm{N}, 140^{\circ} \mathrm{E}-180^{\circ}\right)$ and low-pass filtered to retain periods longer than $10 \mathrm{yr}$. Dashed lines indicate correlations significant at $99 \%$.

face heat flux and geostrophic heat flux divergence in the Kuroshio Extension exhibits maximum correlation $(r=-0.86)$ when the geostrophic heat flux divergence leads by $1-2$ yr (Fig. 7b). Therefore, when heat converges laterally in the upper ocean in the Kuroshio Ex- tension due to anomalous geostrophic currents, SST and the surface heat flux from ocean to atmosphere increase.

\section{c. Basin-scale wind stress curl forcing}

Diagnosis of the upper-ocean heat budget has demonstrated that anomalous horizontal geostrophic heat flux divergence drives decadal SST variability in the Kuroshio Extension. Previous observational and modeling studies have suggested that changes in horizontal geostrophic heat flux divergence near the Kuroshio Extension are driven by changes in basin-scale wind stress curl 3-5 yr earlier (Miller et al. 1998; Deser et al. 1999; Pierce et al. 2001; Seager et al. 2001). These studies have suggested that baroclinic adjustment of the ocean circulation via westward propagation of Rossby waves is responsible for the delay time scale.

Basin-scale wind stress curl forcing in CCSM2 is examined in terms of lag regressions of the annual mean wind stress curl upon the negative of the winter horizontal geostrophic heat flux divergence time series averaged over the Kuroshio Extension based on 10-yr low-pass-filtered anomalies (Fig. 8). The negative of the

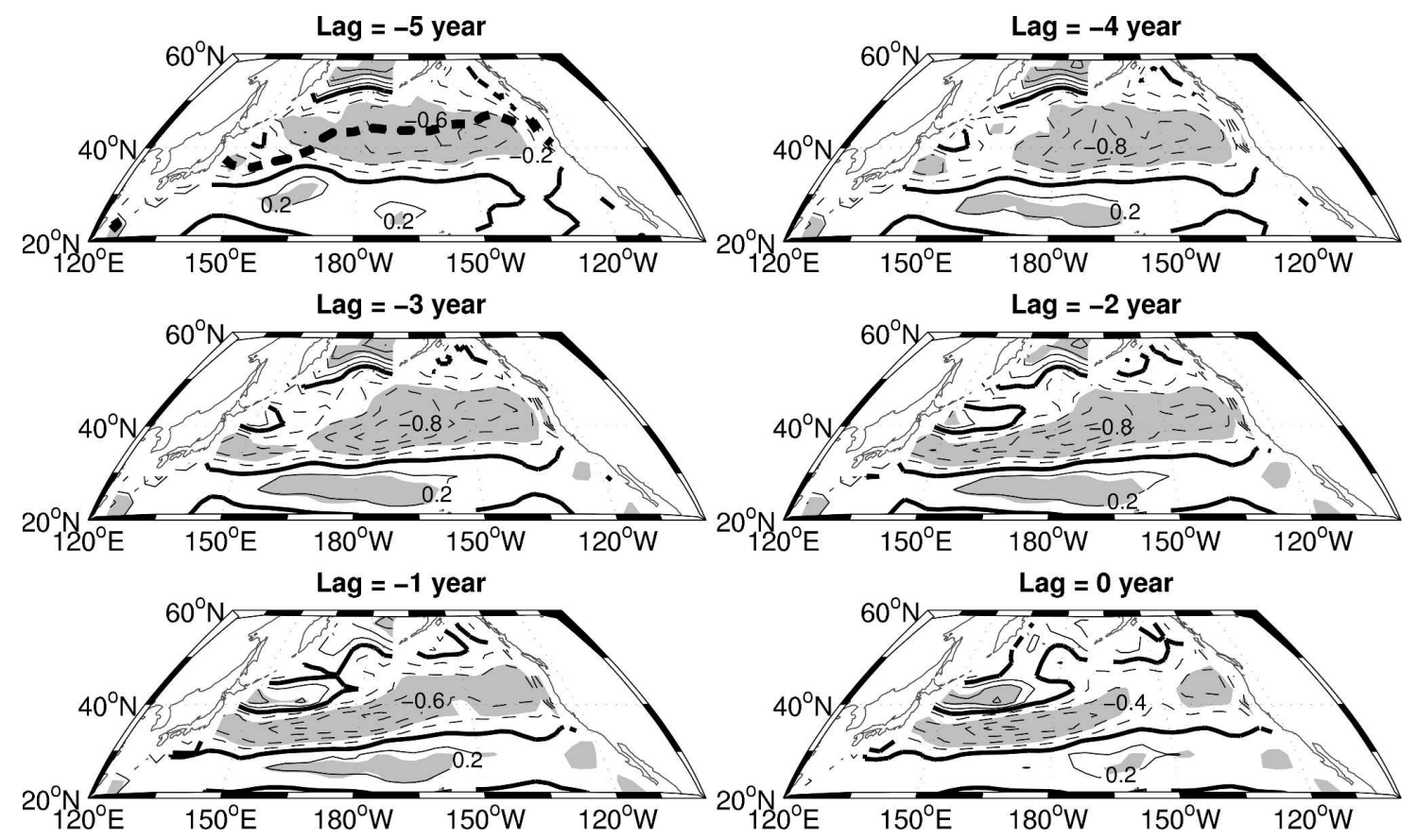

FIG. 8. Lag regressions of annual mean wind stress curl on the negative of DJFM horizontal geostrophic heat flux divergence in the upper $200 \mathrm{~m}$ averaged over the Kuroshio Extension $\left(35^{\circ}-45^{\circ} \mathrm{N}, 140^{\circ} \mathrm{E}-180^{\circ}\right)$. Note that the negative of geostrophic heat flux divergence is used for the index time series to focus on the heat convergence phase (i.e., the positive SST anomaly phase). Both variables are low-pass filtered to retain periods longer than $10 \mathrm{yr}$. Negative lag indicates the wind stress curl is leading geostrophic heat flux convergence. Negative values are contoured with dashed lines. Regression coefficients are standardized to correspond to a one standard deviation change of the geostrophic heat flux divergence time series. Contour interval is $0.2 \times 10^{-8} \mathrm{~N} \mathrm{~m}^{-3}$, and the shadings indicate regressions significant at $99 \%$. Thick dashed contour in the top panel denotes the climatological annual mean zero wind stress curl line. 


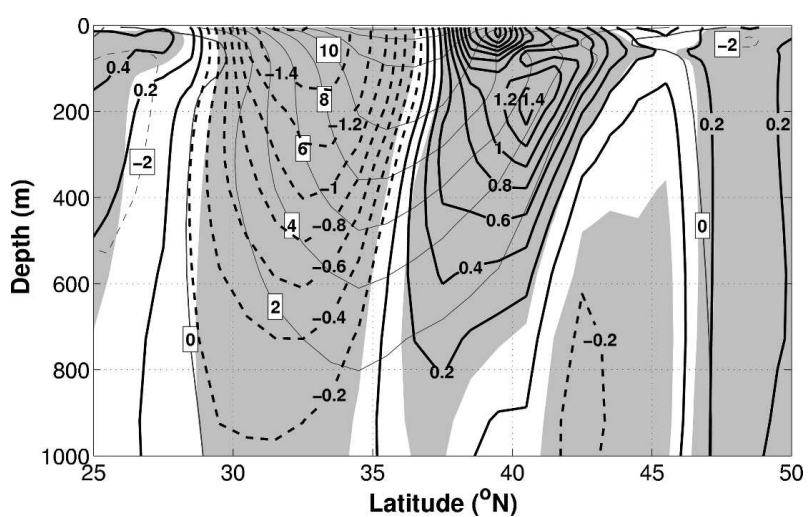

FIG. 9. Simultaneous regression of DJFM subsurface zonal current velocity on the SSTKEI along the meridional section at $150^{\circ} \mathrm{E}$. Both variables are low-pass filtered to retain periods longer than $10 \mathrm{yr}$. Contour interval is $0.2 \mathrm{~cm} \mathrm{~s}^{-1}{ }^{\circ} \mathrm{C}^{-1}$, and the shading indicates regressions significant at $99 \%$. Solid (dashed) contours denote eastward (westward) velocity. Thin contours with boxed labels indicate the climatological winter (DJFM) mean zonal velocity fields. Contour interval for the mean zonal velocity is $2 \mathrm{~cm} \mathrm{~s}^{-1}$.

geostrophic heat flux divergence (= geostrophic heat flux convergence) is used so that the sign is consistent with a positive SST anomaly. The annual-mean wind stress curl is used instead of the winter average because the atmosphere forces the ocean year-round; however, similar results are obtained using winter wind stress curl although the magnitudes are approximately twice as large (not shown). The lag regressions demonstrate that significant basin-scale negative wind stress curl anomalies between $30^{\circ}$ and $50^{\circ} \mathrm{N}$ precede and accompany anomalous geostrophic heat flux convergence in the Kuroshio Extension with maximum values in the central basin when the wind stress curl leads by $3 \mathrm{yr}$. The regression pattern implies a slight northward shift of the zero contour of the total wind stress curl, and thus a northward shift of the boundary between the subpolar and subtropical ocean gyres, which results in anomalous horizontal geostrophic heat flux convergence along the Kuroshio Extension. Simultaneous regression of the subsurface zonal velocity along $150^{\circ} \mathrm{E}$ upon the SSTKEI confirms that the ocean gyre boundary shifts northward in association with positive SST anomalies along the Kuroshio Extension (Fig. 9).

The anomalous wind stress curl forcing pattern that precedes anomalous geostrophic heat flux convergence along the Kuroshio Extension resembles the leading EOF of annual mean wind stress curl over the North Pacific (Fig. 10a). However, the amplitude of the leading EOF pattern is approximately 4 times greater than that of the forcing pattern. The power spectrum of the associated PC time series is approximately consistent
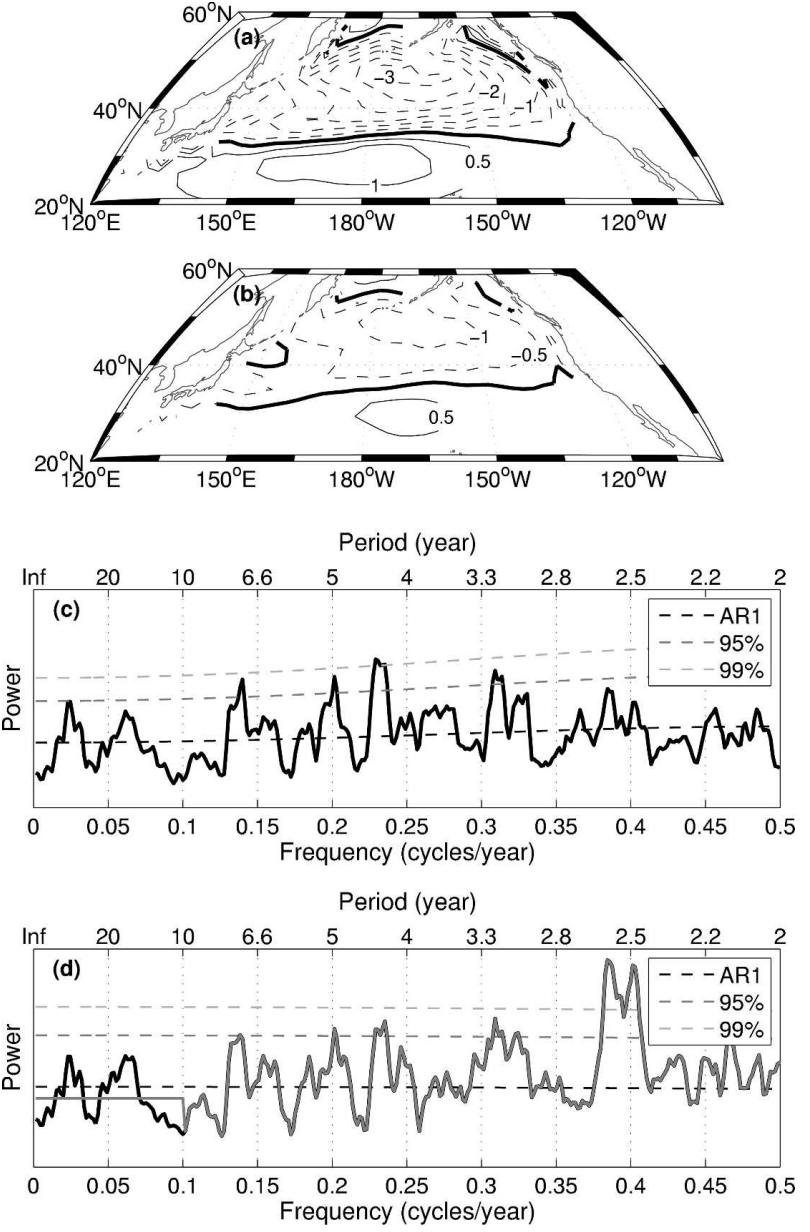

FIG. 10. (a) Leading EOF pattern of unfiltered annual mean wind stress curl anomalies over the North Pacific $\left(20^{\circ}-60^{\circ} \mathrm{N}\right)$. The leading EOF mode explains 19\% of the total variance. Amplitude corresponds to a one standard deviation change of the corresponding PC time series. Contour interval is $0.5 \times 10^{-8} \mathrm{~N} \mathrm{~m}^{-3}$. (b) Same as in (a), but for low-pass-filtered (periods longer than 10 yr) wind stress curl anomalies. This EOF mode explains $18 \%$ of the total variance. (c) Power spectrum of the leading PC time series based on unfiltered data. The best-fit AR1 spectrum and 95\% and $99 \%$ significant levels with respect to the AR1 spectrum are shown as dashed lines. (d) Power spectrum of the monthly forcing time series for the linear Rossby wave model. Note that the frequency range higher than 0.5 cpy is not shown. Horizontal gray line at periods longer than $10 \mathrm{yr}$ is the power spectrum used for the calculation shown in Fig. 13d.

with white noise, with nearly equal power at all frequencies (Fig. 10c). It is interesting to note that the power spectrum exhibits weak $\sim 16$ and $\sim 40$ yr peaks, although they are not significant nor are they greater compared to other peaks at higher frequencies. When the annual mean wind stress curl anomalies are lowpass filtered to retain only periods longer than $10 \mathrm{yr}$, the leading EOF is similar in pattern to that based on unfiltered data but the amplitudes are reduced by a 
factor of $\sim 2.5$, consistent with the relative proportion of power in the unfiltered PC time series at periods longer than $10 \mathrm{yr}$ (Figs. 10b,c).

\section{d. Linear Rossby wave model}

We next examine the explicit linkage between anomalous wind stress curl forcing and decadal ocean current variability along the Kuroshio Extension using a simple linear baroclinic Rossby wave model. The large-scale, baroclinic ocean response to wind stress curl forcing can be approximated using a 11/2-layer reduced gravity model. Under the long-wave approximation, the linear vorticity equation of the model is

$$
\frac{\partial h}{\partial t}-C_{\mathrm{RW}} \frac{\partial h}{\partial x}=-\frac{g^{\prime}}{\rho_{0} g f} \mathbf{k} \cdot \boldsymbol{\nabla} \times \boldsymbol{\tau}-\varepsilon h,
$$

where $h$ is the sea surface height ( $\mathrm{SSH}), C_{\mathrm{RW}}$ is the speed of the long baroclinic Rossby waves, $g^{\prime}$ is the reduced gravity, $\rho_{0}$ is the reference density of seawater, $f$ is the Coriolis parameter, $\mathbf{k}$ is the unit vector in the vertical direction, $\boldsymbol{\nabla} \times \boldsymbol{\tau}$ is the wind stress curl, and $\varepsilon$ is the Newtonian dissipation rate. An analytic solution as shown in Eq. (3) can be obtained by integrating Eq. (2) from the eastern boundary $\left(x_{e}\right)$ along the baroclinic Rossby wave characteristics. The boundary condition at the eastern boundary is assumed to be $h\left(x_{e}, t\right)=0$, which is reasonable for our purposes (Fu and Qiu 2002):

$$
\begin{aligned}
h(x, t)= & \frac{g^{\prime}}{\rho_{0} g f C_{\mathrm{RW}}} \\
& \times \int_{x_{e}}^{x} \mathbf{k} \cdot \boldsymbol{\nabla} \times \boldsymbol{\tau}\left(x^{\prime}, t+\frac{x-x^{\prime}}{C_{\mathrm{RW}}}\right) \exp \left[\varepsilon \frac{x-x^{\prime}}{C_{\mathrm{RW}}}\right] d x^{\prime} .
\end{aligned}
$$

SSH anomalies are hindcast for each latitude independently using Eq. (3). The wind stress curl forcing is obtained by projecting the lag 3-yr regression pattern from Fig. 8 upon the full CCSM2 wind stress curl anomalies in each month. Similar results are obtained when the leading wind stress curl EOF is used instead of the lag 3-yr regression. The Rossby wave speeds at each latitude are estimated from the CCSM2 SSH anomalies using the method described in Chelton and Schlax (1996); see Fig. 11. As in Chelton and Schlax, the time-longitude plots of monthly SSH are examined visually to identify regions of unambiguous westward propagation that span at least $30^{\circ}$ of longitude. Note that the regions of westward propagation were found only to the east of the date line for the latitudes with strong eastward advection near $40^{\circ} \mathrm{N}$. The estimated CCSM2 Rossby wave speeds are generally consistent with previous empirical estimates based on satellite al-

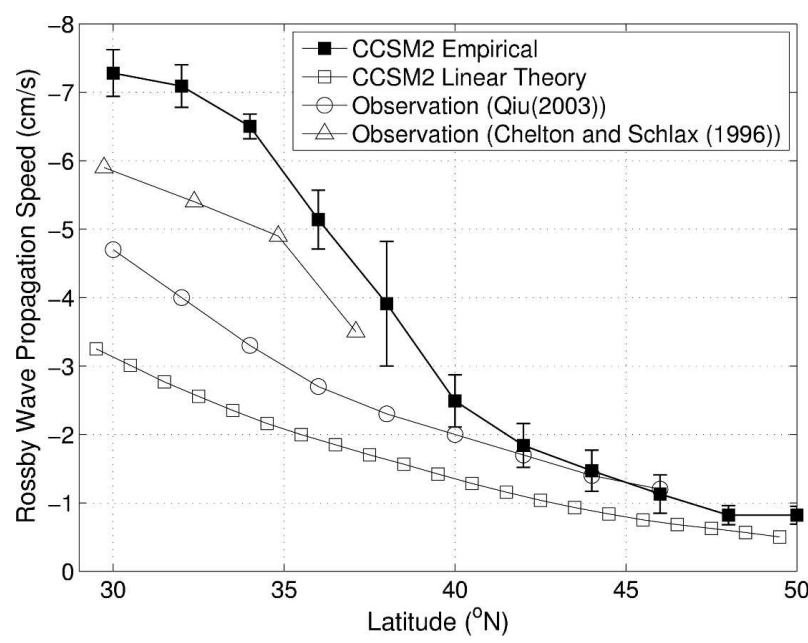

FIG. 11. Phase speeds of first baroclinic mode Rossby wave in the North Pacific as a function of latitude, derived from the sources indicated in the legend.

timetry observations (Chelton and Schlax 1996; Qiu 2003), although they are larger in magnitude south of $40^{\circ} \mathrm{N}$. Discrepancies between the empirical estimates and theoretical estimates based on the density stratification are evident in CCSM2, similar to observations (Chelton and Schlax 1996). The dissipation rate $(\varepsilon)$ is a poorly known quantity. Here $\varepsilon^{-1}=12 \mathrm{yr}$ is used based on the hindcast skill of the SSH anomalies in the Kuroshio Extension. Qiu (2002) and Schneider et al. (2002) estimated $\varepsilon^{-1}$ to be 6 and $4 \mathrm{yr}$, respectively, based on similar strategies. We also obtained the highest hindcast skill using $\varepsilon^{-1}=6 \mathrm{yr}$ when the CCSM2 and the hindcasted SSH time series are not low-pass filtered. However, when both SSH time series are low-pass filtered to retain periods longer than $10 \mathrm{yr}$, the highest skill is obtained with $\varepsilon^{-1}=12 \mathrm{yr}$. The question of whether the dissipation rate is frequency dependent is beyond the scope of this paper.

Prior to an assessment of hindcasted SSH anomalies against the CCSM2 SSH anomalies, the correlation between the horizontal geostrophic heat flux divergence and the SSH anomalies in CCSM2 should be explicitly demonstrated to ensure the relevance of SSH anomalies to the decadal variability of interest. Regression of SSH anomalies upon the time series of the negative of averaged anomalous horizontal geostrophic heat flux divergence in the Kuroshio Extension exhibits maximum positive anomalies collocated with the maximum meridional gradient of the climatological mean SSH in the Kuroshio Extension $\left(34^{\circ}-43^{\circ} \mathrm{N}, 140^{\circ} \mathrm{E}-180^{\circ}\right)$; see Fig. 12. The maximum positive SSH anomalies in the Kuroshio Extension are located in the region slightly south of the maximum SST anomalies (recall Fig. 1a). 


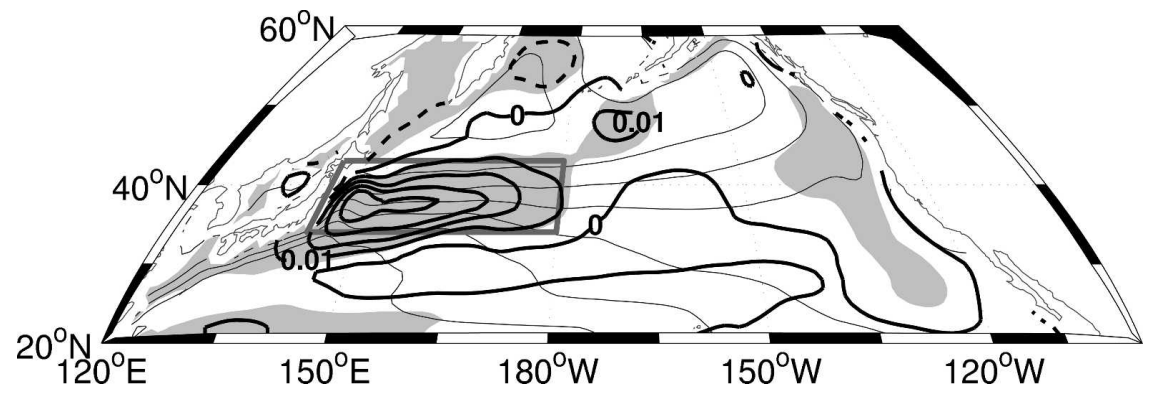

FIG. 12. Simultaneous regressions of winter (DJFM) SSH on the negative of horizontal geostrophic heat flux divergence in the upper $200 \mathrm{~m}$ averaged over the Kuroshio Extension $\left(35^{\circ}-45^{\circ} \mathrm{N}, 140^{\circ} \mathrm{E}-180^{\circ}\right)$. Note that the negative of geostrophic heat flux divergence is used for the index time series to focus on the heat convergence phase (i.e., positive SST anomaly phase). Both variables are low-pass filtered to retain periods longer than $10 \mathrm{yr}$. Negative values are contoured with dashed lines. Regression coefficients are standardized to correspond to a one standard deviation change of the geostrophic heat flux divergence time series. Contour interval is $0.01 \mathrm{~m}$, and shading indicates regressions significant at $99 \%$. Thin contours denote the climatological winter SSH field. The contour interval for the mean SSH is $0.2 \mathrm{~m}$. Gray solid box $\left(34^{\circ}-43^{\circ} \mathrm{N}, 140^{\circ} \mathrm{E}-180^{\circ}\right)$ denotes the averaging region for the $\mathrm{SSH}$ index time series shown in Fig. 13.

The correlation coefficient between the time series of hindcast SSH from the Rossby wave model and CCSM2 SSH anomalies averaged over the region $34^{\circ}-43^{\circ} \mathrm{N}$, $140^{\circ} \mathrm{E}-180^{\circ}$ is 0.63 , which suggests a reasonable hindcast skill of the linear Rossby wave model (Fig. 13a). The hindcast SSH anomalies also reproduce reasonably well the power spectrum of the CCSM2 SSH anomalies with peaks near 16 and $40 \mathrm{yr}$ (Figs. 13b,c). The hindcast SSH anomalies are not unduly sensitive to the uncertainties in the estimates of the Rossby wave speeds and dissipation rates as shown in Fig. 13c.

The hindcast skill of the linear Rossby wave model forced with the diagnosed wind stress curl forcing pattern explicitly demonstrates that the wind stress curl forcing pattern is indeed appropriately diagnosed and that the decadal variability in the Kuroshio Extension is associated with changes in the basin-scale wind stress curl forcing via baroclinic adjustment of the ocean gyres. Given the confidence in the hindcast skill of the Rossby wave model, we next examine the role of the low-frequency power and the existence of the weak $\sim 16$ and $\sim 40$ yr spectral peaks in the wind stress curl forcing (Fig. 10d). SSH hindcast using only the 10-yr low-pass filtered wind stress curl forcing is almost identical to that obtained using the full unfiltered monthly forcing (Fig. 13d). This suggests that only the lowfrequency part of the wind stress curl forcing is relevant to the decadal variability in the Kuroshio Extension, even though the power in the wind stress curl forcing is almost equally distributed throughout the whole frequency range. To examine the role of the weak $\sim 16$ and $\sim 40 \mathrm{yr}$ spectral peaks in the wind stress curl forcing, we replaced the power in the wind stress curl forc- ing at periods longer than $10 \mathrm{yr}$ to its average value within this frequency band, thus removing the spectral peaks but keeping the total low-frequency variance unchanged (see Fig. 10d). The resulting SSH hindcast exhibits a canonical red noise spectrum without any lowfrequency spectral peaks (Fig. 13d). These results suggest that the weak low-frequency spectral peaks in the wind stress forcing are essential for producing the significant commensurate spectral peaks in SSH.

\section{e. Atmospheric response to decadal SST anomalies in the Kuroshio Extension}

We have established that basin-scale anomalous wind stress curl forcing causes decadal SST anomalies in the Kuroshio Extension. Are there local and basin-scale atmospheric responses to the SST anomalies in the Kuroshio Extension that could establish a closed loop of atmosphere-ocean coupled decadal variability such as that proposed by Latif and Barnett (1994) and Neelin and Weng (1999)? Figure 14 shows SST, net surface heat flux, precipitation, and wind stress curl anomalies along $40^{\circ} \mathrm{N}$ as a function of longitude and time. Note that all variables have been low-pass filtered to retain periods longer than $10 \mathrm{yr}$. SST anomalies clearly exhibit 16 -yr variability as well as eastward propagation in the western half of the basin, consistent with Fig. 3. Net surface heat flux anomalies propagate along with the SST anomalies and respond to, rather than force, them as discussed previously. The latent heat flux components dominate the net surface heat flux response (not shown). Precipitation anomalies also exhibit eastward propagation with enhanced (diminished) precipitation over warm (cool) SST anomalies. Finally, wind stress 

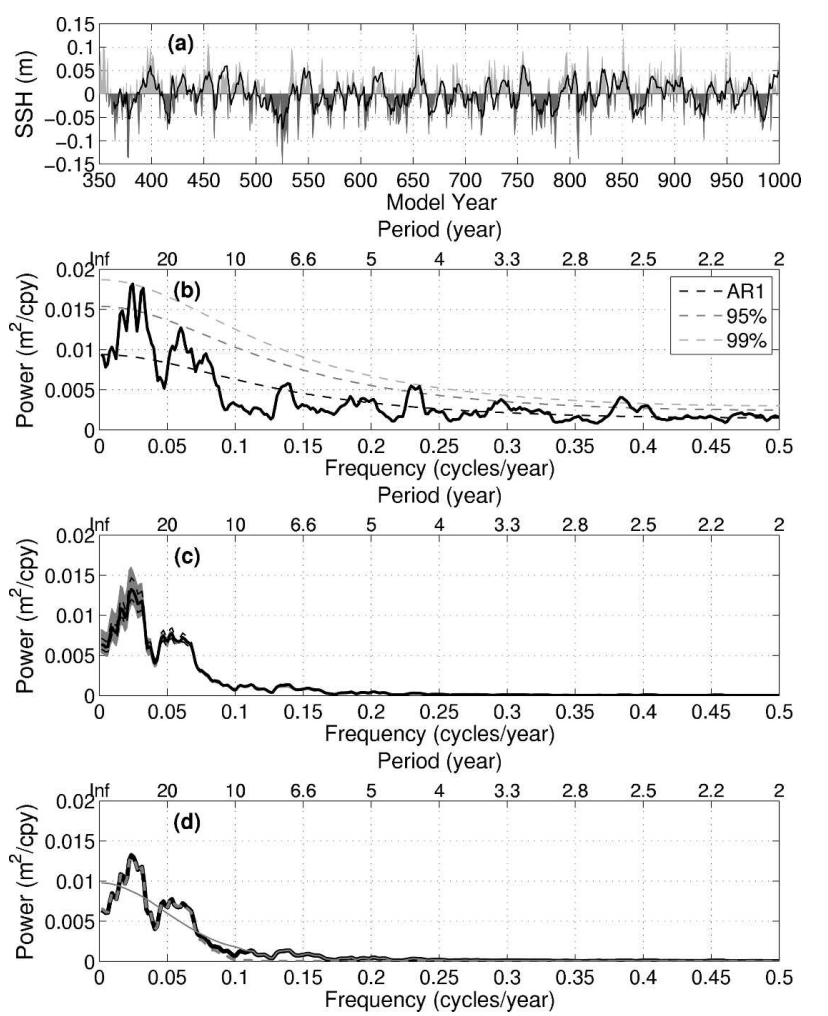

FIG. 13. Winter SSH anomalies averaged over $34^{\circ}-43^{\circ} \mathrm{N}$, $140^{\circ} \mathrm{E}-180^{\circ}$. (a) Time series of the CCSM2 SSH (shading) and the SSH hindcast using the linear Rossby wave model (solid curve) forced by the wind stress curl forcing pattern and a damping time scale of $12 \mathrm{yr}$. The correlation coefficient between the two time series is 0.63 . When both time series are low-pass filtered for longer than $10 \mathrm{yr}$, the correlation coefficient is 0.84 . (b) Power spectrum of the CCSM2 SSH. The best-fit AR1 spectrum and $95 \%$ and $99 \%$ significant levels with respect to the AR1 spectrum are plotted with dashed lines. (c) Power spectrum of the Rossby wave model hindcast SSH (solid line). Gray shading denotes uncertainties of $\varepsilon^{-1}$ with a range of \pm 2 yr. Dashed lines denote uncertainties in the empirical estimates of the Rossby wave speed as shown with vertical bars in Fig. 11. (d) Solid black curve is repeated from (c). The dashed gray curve is from the Rossby wave model using low-pass-filtered forcing. The thin gray solid curve is from the Rossby wave model using flat low-frequency forcing (see Fig. 10d).

curl anomalies are also positively correlated with the SST anomalies, although the relation is not as strong as for net surface heat flux and precipitation.

Whether these apparent local atmospheric responses to decadal SST variations can grow into basin-scale responses is crucial to the existence of a coupled atmosphere-ocean mode. An estimate of the basin-scale annual mean wind stress curl response may be obtained by means of lag regressions on the SSTKEI when the wind stress curl lags the SSTKEI by $1 \mathrm{yr}$. Unlike the simultaneous regression, which consists of both response and forcing, the 1-yr lag regression reflects mainly the response since unfiltered wind stress curl anomalies contain practically no memory from one year to the next. Note that the response pattern is further scaled by the ratio of the standard deviation of $10-\mathrm{yr}$ low-pass filtered SSTKEI to that of unfiltered SSTKEI to allow a direct comparison to the forcing pattern. The response pattern is broadly similar to the forcing pattern but of opposite sign and approximately $65 \%$ in magnitude (Figs. 15a,b). One noticeable difference is that the maximum anomaly of the response pattern is located west of the date line along $40^{\circ} \mathrm{N}$, farther west and more meridionally confined than that of the forcing pattern. Winter wind stress curl forcing and response patterns are consistent with their annual mean counterparts but their amplitudes are approximately twice as large (Figs. 15c,d).

Two additional experiments are performed to examine the robustness of the wind stress curl response pattern inferred from lag regression analysis: CAM2, the stand-alone atmospheric general circulation model component of CCSM2, forced with decadal SST anomalies in the Kuroshio Extension taken from CCSM2, and CAM2, coupled to an entraining ocean mixed layer model forced with decadal geostrophic heat flux divergence anomalies in the Kuroshio Extension taken from CCSM2. The equilibrium responses in both experiments are examined by computing the differences between the mean of 100-yr perturbation integrations with specified SST and geostrophic heat flux divergence anomalies, respectively, and the mean of 150 -yr control integrations without specified anomalies. The ocean mixed layer model consists of a grid of independent column models aligned with the atmospheric model grid, with a uniform mixed layer atop a multilayered model that represents conditions in the pycnocline (Alexander et al. 2000; Cassou et al. 2007). It has 36 vertical layers within the upper $1500 \mathrm{~m}$. [The reader is referred to Cassou et al. (2007) and http:// www.cgd.ucar.edu/cas/cdeser/REMsupfig.html for a detailed description of the ocean mixed layer model and the control integration of the CAM2-ocean mixed layer model experiment.]

The root-mean-square of 10-yr low-pass-filtered CCSM2 SST anomalies for each month is specified only in the Kuroshio Extension for the perturbation integration of the stand-alone CAM2. The annual mean of the specified SST anomalies is shown in Fig. 16a. The annual mean wind stress curl response (Fig. 16b) exhibits a similar shape and slightly greater magnitude in the western half of the basin compared to the response estimated by lag regression. The response is weaker in the eastern half of the basin probably because the SST anomalies are specified only in the Kuroshio Extension, 
(a) SST

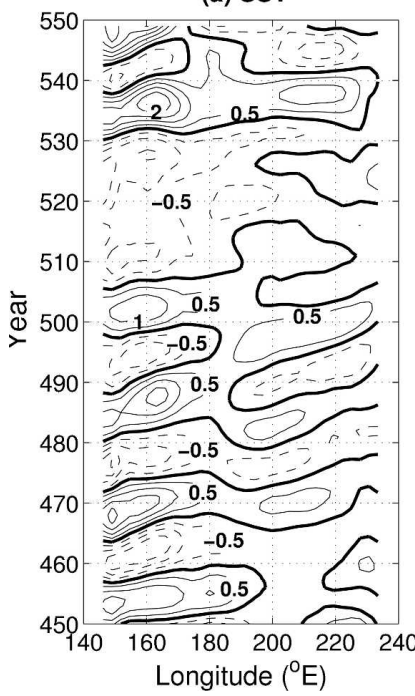

(b) Qnet

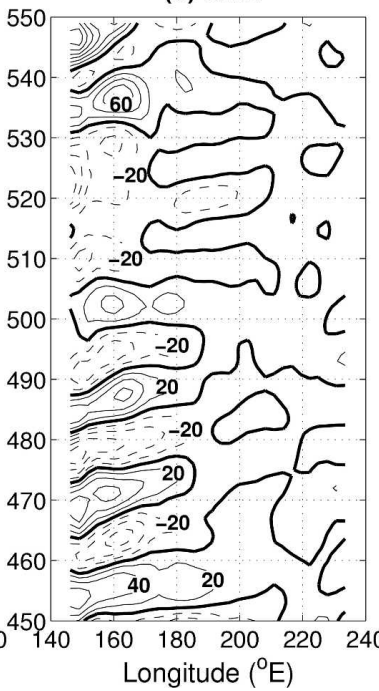

(c) Precipitation

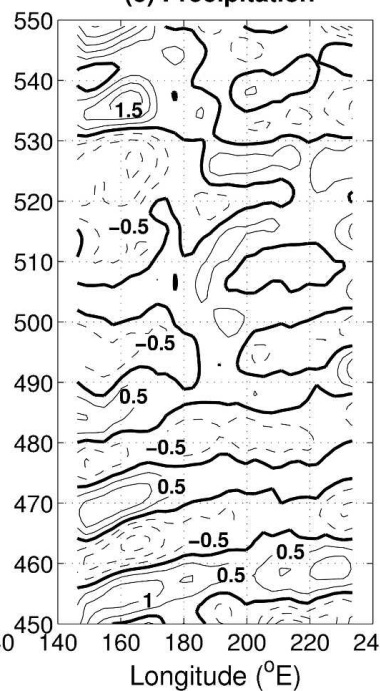

(d) Wind Stress Curl

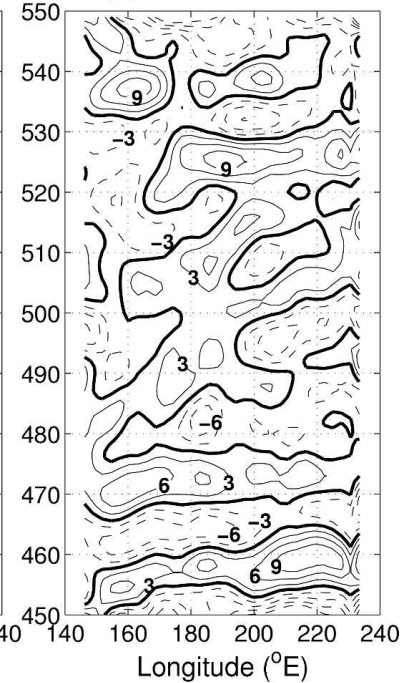

FIG. 14. Hovmöller plot of winter (a) SST, (b) net surface heat flux, (c) precipitation, and (d) wind stress curl anomalies along $40^{\circ} \mathrm{N}$ for years 450-550. All variables are low-pass filtered to retain periods longer than $10 \mathrm{yr}$. Positive (negative) anomalies are plotted with solid (dashed) contours. Contour intervals are (a) $0.5^{\circ} \mathrm{C}$, (b) $20 \mathrm{~W} \mathrm{~m}^{-2}$, (c) $0.5 \mathrm{~mm} \mathrm{day}^{-1}$, and (d) $3 \times 10^{-8} \mathrm{~N} \mathrm{~m}^{-3}$.

whereas in CCSM2 they propagate eastward to expand across the date line (Fig. 4).

The root-mean-square of 10-yr low-pass filtered CCSM2 geostrophic heat flux divergence anomalies in the upper $1000 \mathrm{~m}$ for each month is specified in the Kuroshio Extension for the perturbation integration of the CAM2-ocean mixed layer model. The SST response is similar to the SST anomalies specified in stand-alone CAM2 integration, with a slight eastward extension due to atmospheric processes (Fig. 16c). The annual mean wind stress curl response is similar in pattern and magnitude to both the stand-alone CAM2 in- tegration and CCSM2, giving confidence in the robustness of the results.

\section{Discussion}

\section{a. Decadal time-scale selection}

The basin-crossing time of first baroclinic mode Rossby waves has often been suggested as a source of the decadal time scale in the North Pacific (Latif and Barnett 1994; Pierce et al. 2001). This argument may be relevant for the time scale selection of the 16-yr variability in CCSM2. As already described, a 3-5-yr delay

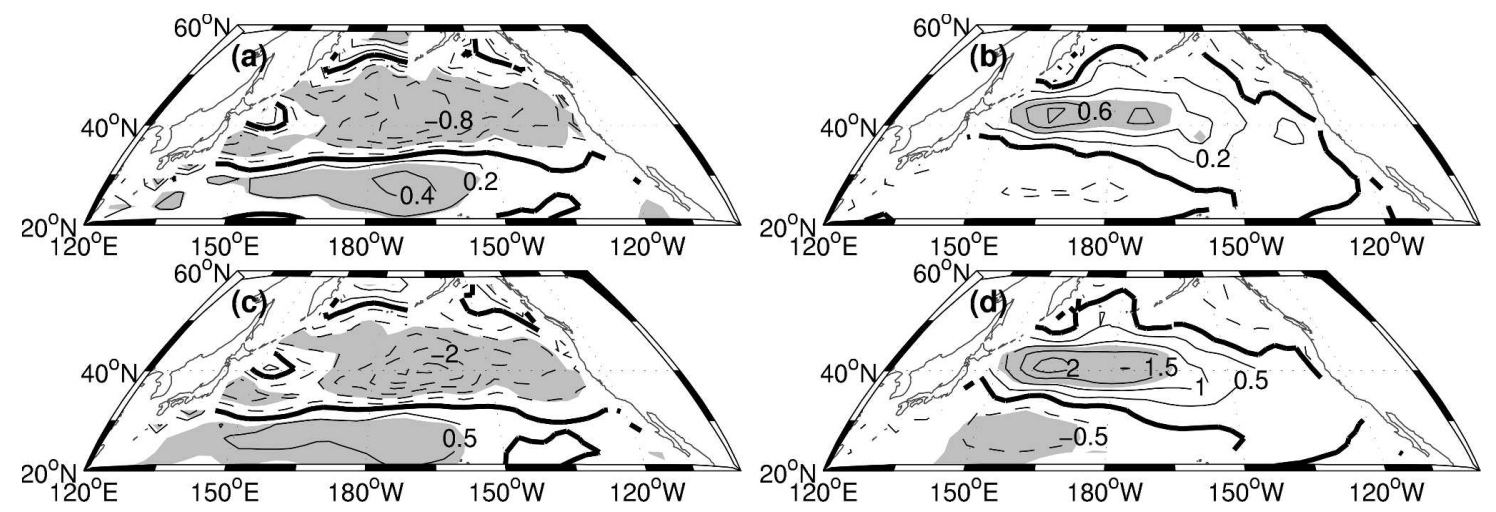

FIG. 15. Regression of wind stress curl anomalies on the winter normalized SSTKEI. (a) Annual mean wind stress curl leading SST Index by 4 yr; both variables are smoothed with a 10-yr low-pass filter. (b) Annual mean wind stress curl lagging the SST index by $1 \mathrm{yr}$ based on unfiltered data. The unfiltered regression pattern is further scaled by the ratio of the standard deviation of 10-yr low-pass-filtered SST index to that of unfiltered SST index. (c), (d) As in (a), (b) but for winter (DJFM). Contour intervals are $0.2 \times 10^{-8} \mathrm{~N} \mathrm{~m}^{-3}$ for (a), (b) and $0.5 \times 10^{-8} \mathrm{~N} \mathrm{~m}^{-3}$ for (c), (d). Negative values are dashed and shading indicates regressions significant at $99 \%$. 


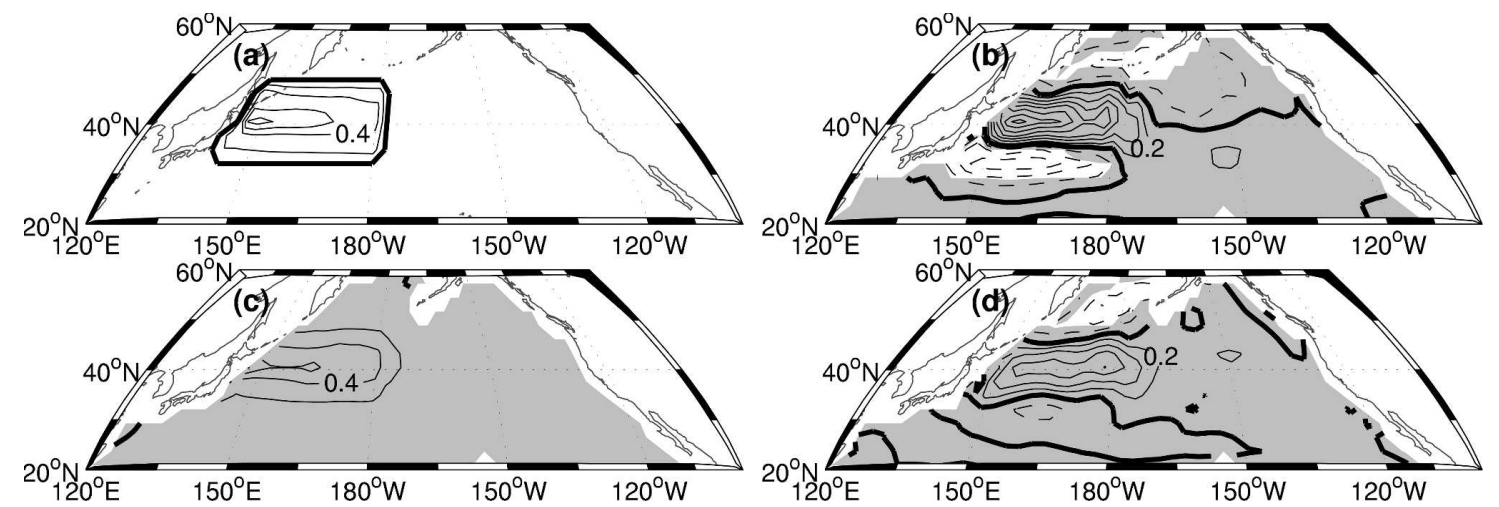

FIG. 16. (a) Annual mean of the SST anomalies specified as forcing of stand-alone CAM2 integration. (b) Annual mean wind stress curl response from stand-alone CAM2 integration. (c) Annual mean SST response from CAM2-ocean mixed layer model integration with specified geostrophic heat flux divergence anomalies in the Kuroshio Extension. (d) Annual mean wind stress curl response from CAM2-ocean mixed layer model integration. Contour intervals are $0.2^{\circ} \mathrm{C}$ for the SST and $0.2 \times 10^{-8} \mathrm{~N} \mathrm{~m}^{-3}$ for the wind stress curl. Negative values are dashed and shading indicates response significant at $99 \%$.

is found between the wind stress curl forcing and the anomalous geostrophic heat flux divergence in the Kuroshio Extension via first baroclinic mode Rossby waves. An additional delay of $1-2 \mathrm{yr}$ is found between the anomalous geostrophic heat flux divergence and the SST and net surface heat flux response in the Kuroshio Extension. Finally, another 1-2 yr is needed for the SST and net surface heat flux anomalies to expand eastward where they may more effectively induce a basin-scale wind stress curl response pattern that is similar in pattern but opposite in sign to the wind stress curl forcing. The sum of these three delay factors could result in an 8 -yr half-cycle.

Spatial resonance between stochastic atmospheric forcing and the oceanic response has also been suggested as a possible source of the decadal time scale (Jin 1997; Saravanan and McWilliams 1998; Neelin and Weng 1999). These theories require a zonal wavenumber-one atmospheric forcing pattern across the basin. However, the wind stress curl forcing pattern in CCSM2 exhibits one sign across the basin (e.g., zonal wavenumber zero). Further, the Rossby wave model hindcast forced by the flat low-frequency wind stress curl forcing did not reproduce the decadal spectral peaks, confirming that a monopolar forcing pattern does not produce decadal resonance. Pierce et al. (2001) and Schneider et al. (2002) also reported that the spatial resonance mechanism could not reproduce decadal spectral peaks in the Kuroshio Extension in the ECHO2 and CSM1 integrations.

Recently, Qiu (2003) proposed a resonance mechanism due to the difference in Rossby wave speeds between the southern and northern flanks of the Kuroshio Extension, a distance of about $\sim 4^{\circ}-8^{\circ}$ in latitude. Qiu's analytical solution, when calculated using the estimated
Rossby wave speeds and other parameters appropriate for the CCSM2, reproduces a decadal peak around $16 \mathrm{yr}$ for the meridional SSH difference $(\Delta \mathrm{SSH})$ across the Kuroshio Extension with an acceptable range of sensitivity to the choice of parameters (not shown). However, the Qiu mechanism is unlikely for CCSM2 since $\Delta \mathrm{SSH}$ across the Kuroshio Extension in CCSM2 does not exhibit a distinct 16-yr spectral peak and the variability of $\Delta \mathrm{SSH}$ in the Qiu model represents a strengthening/weakening of the gyre rather than a meridional shift of gyre boundaries.

It is therefore likely that the decadal time scale in CCSM2 is selected by coupled atmosphere-ocean processes within the North Pacific. Two key results support the existence of a coupled atmosphere-ocean oscillation within the North Pacific in CCSM2: the linear Rossby wave model results and the wind stress curl response to SST anomalies in the Kuroshio Extension. The linear Rossby wave model results illustrate that the weak decadal spectral peaks in the wind stress curl forcing are necessary for producing the corresponding spectral peaks in SSH (and by inference, SST). The wind stress curl response pattern inferred from lagregression analysis is similar in structure but opposite in sign and about $35 \%$ weaker than the forcing pattern, consistent with the responses obtained from the standalone CAM2 and CAM2-ocean mixed layer model experiments. A deterministic coupled atmosphere-ocean mode as suggested by Latif and Barnett (1994) is unlikely the case for CCSM2 because the wind stress curl response is weaker than the forcing and the decadal variability in the wind stress curl is not as regular as it is in SST. However, according to the theory of Neelin and Weng (1999), even a weak and irregular atmospheric response to decadal SST anomalies enhances 
the power of decadal peaks in SST originally introduced by ocean dynamics, and thus is sufficient to maintain a coupled mode of decadal variability.

It is plausible that the identical sets of processes described above to explain the 16-yr time scale may be applied to explain the 40-yr time scale if the first baroclinic mode Rossby waves are replaced by slower second baroclinic mode Rossby waves. Theory suggests that the speed of the $n$th baroclinic mode Rossby wave decreases by a factor of $n^{-2}$ (Chelton et al. 1998), which implies a basin-crossing time of 12-20 yr for the second baroclinic mode Rossby waves. However, as pointed out by Liu (1999), second- (and higher) mode Rossby waves generally propagate southwestward along the mean subduction pathway rather than directly westward because of the Doppler effect. However, since the empirically estimated speed of first baroclinic Rossby waves in CCSM2 is faster than observational estimates for most latitudes, the second baroclinic Rossby waves in the CCSM2 could still be faster than the mean advection in the Kuroshio Extension, negating the Doppler effect. Further work is needed to investigate whether second baroclinic mode Rossby waves are responsible for the 40-yr variability in CCSM2.

Remote forcing from the tropical Pacific via atmospheric teleconnections has been suggested as a source of North Pacific decadal variability in nature (Newman et al. 2003; Deser et al. 2004; Schneider and Cornuelle 2005). In CCSM2, however, regressions of 10-yr lowpass filtered winter precipitation and SST anomalies over the tropical Indo-Pacific on the SSTKEI are weak and insignificant (not shown). Regressions of unfiltered data are also weak but statistically significant (correlation coefficients $\sim 0.2$ ), with negative precipitation anomalies in the Pacific and positive anomalies in the eastern Indian Ocean along the equator with magnitudes $\sim 0.2 \mathrm{~mm}$ day $^{-1}$ per standard deviation change in the SSTKEI (not shown). The pattern broadly resembles that associated with cold ENSO events in the model; however, the precipitation magnitudes are only about $15 \%$ of those associated with ENSO, while the corresponding North Pacific SLP response is about $70 \%$ of that associated with ENSO. These results suggest that tropical forcing of North Pacific decadal variability in CCSM2 is not likely to be important. Pierce et al. (2001) also suggested the tropical remote forcing mainly projects onto interannual variability rather than decadal and lower frequency variability in the ECHO2 and CSM1.

\section{b. 1976/77 shift of the Pacific decadal oscillation}

The 1976/77 regime shift is probably the most studied aspect of the observed PDO (Miller et al. 1994; Deser et al. 1999; Xie et al. 2000; Seager et al. 2001). We attempt to compare elements of the observed and model hindcast features of the 1976/77 PDO shift with the decadal variability in CCSM2 in order to assess the realism of the coupled model and to shed light on the mechanisms responsible for the observed PDO, an aspect hindered by the limited length of available observations. Several aspects of CCSM2's decadal variability are consistent with the observed 1976/77 PDO shift, including: the basin-scale structure of the wind stress curl forcing centered along $30^{\circ}-50^{\circ} \mathrm{N}$ with maximum amplitude near $40^{\circ} \mathrm{N}, 170^{\circ} \mathrm{W}$, which represents a meridional shift of the zero wind stress curl position (Miller et al. 1998; Deser et al. 1999; Xie et al. 2000; Seager et al. 2001); the 3-5-yr delay between the wind stress curl forcing and the SST response in the Kuroshio Extension caused by a meridional shift of the boundary between the subpolar and subtropical gyres and associated anomalous divergence of the horizontal geostrophic heat flux (Miller et al. 1998; Deser et al. 1999; Xie et al. 2000; Seager et al. 2001); and surface heat flux damping of the SST anomalies in the Kuroshio Extension (Seager et al. 2001; Tanimoto et al. 2003; Kelly 2004).

Other aspects of CCSM2's decadal variability, in particular the nature of the wind stress curl response to SST anomalies in the Kuroshio Extension, are more challenging to confirm against the observed 1976/77 PDO shift, primarily because of the difficulty of isolating an atmospheric response in observations and the inconsistent results among atmospheric models forced with prescribed SST anomalies (Kushnir et al. 2002). Epoch difference maps of the wind stress curl between the periods before and after the 1976/77 shift, which primarily present the wind stress curl forcing pattern, contain a hint of a local wind stress curl response in the Kuroshio Extension in the form of a patch of negative anomalies embedded within the pattern of basinwide positive anomalies, similar to our CCSM2 results (Deser et al. 1999; Seager et al. 2001). Whether this inferred wind stress curl response to SST anomalies along the Kuroshio Extension associated with the 1976/ 77 shift is strong enough to sustain a coupled oceanatmosphere mode of decadal variability similar to that in CCSM2 requires further investigation. We note that many studies have suggested that the tropical IndoPacific also contributed to the 1976/77 shift over the North Pacific via an atmospheric bridge (Newman et al. 2003; Deser et al. 2004; Schneider and Cornuelle 2005).

The resolution of CCSM2 is not high enough to fully resolve the narrow and complex SST frontal structures in the Kuroshio Extension. Recent high-resolution satellite observations and eddy-resolving ocean general 
circulation models indicate two separate frontal zones; the stronger Oyashio Front near $40^{\circ} \mathrm{N}$ and weaker Kuroshio Front near $35^{\circ} \mathrm{N}$ (Nakamura and Kazmin 2003; Taguchi et al. 2005; Nonaka et al. 2006). The high-resolution ocean models also suggest that oceanic adjustment to wind stress curl variability deviates from linear Rossby wave dynamics and the role of mesoscale eddies becomes increasingly important near these narrow frontal zones. However, these high-resolution ocean models and observations agree on that the SST anomalies in the Kuroshio Extension related to 1976/77 shift is due to meridional displacement of the fronts and the maximum SST anomalies are located along $40^{\circ} \mathrm{N}$ as simulated in the CCSM2. The meridional shift of a narrower frontal zone would produce more localized and larger amplitude SST anomalies than a broader frontal zone, which in turn could affect the intensity of the atmospheric response.

\section{Conclusions}

North Pacific decadal variability in CCSM2 is examined from a 650 -yr segment of the 1000-yr control integration of present-day climate. The leading EOF of winter SST anomalies exhibits a PDO-like horseshoe pattern with maximum variance concentrated along the Kuroshio Extension. SST anomalies averaged over the Kuroshio Extension region exhibit significant lowfrequency spectral peaks at approximately 16 and $40 \mathrm{yr}$. Subsurface temperature anomalies within the upper $1000 \mathrm{~m}$ also exhibit decadal variability coherent with the SST anomalies. Upper-ocean lateral geostrophic heat flux divergence caused by a meridional shift of Kuroshio Extension is responsible for the decadal SST variability in the Kuroshio Extension. Local surface heat flux and Ekman heat flux divergence anomalies act as damping and positive feedback, respectively, in response to the SST anomalies.

The meridional shift of the Kuroshio Extension is forced by basin-scale wind stress curl anomalies 3-5 yr earlier. The wind stress curl forcing has one sign between $30^{\circ}$ and $50^{\circ} \mathrm{N}$ centered near $170^{\circ} \mathrm{W}$, which is similar to the leading EOF pattern of the wind stress curl. This forcing pattern represents a meridional shift of the zero wind stress curl line rather than an in situ change in amplitude of the Aleutian low. A simple linear Rossby wave model was employed to illustrate that only the low-frequency ( $>10$-yr period) portion of the wind stress curl forcing is relevant to the oceanic decadal variability in the Kuroshio Extension, even though the overall shape of the spectrum of wind stress curl forcing is similar to white noise. Furthermore, insignificant low-frequency spectral peaks at around $16 \mathrm{yr}$ and $40 \mathrm{yr}$ in the wind stress curl forcing turned out to be necessary to reproduce the significant decadal oceanic (SSH) peaks in the Kuroshio Extension. The wind stress curl response pattern to the SST anomalies in the Kuroshio Extension, inferred from lag regression analysis, exhibits a similar spatial structure to the wind stress curl forcing pattern with opposite sign and $\sim 35 \%$ decrease in amplitude. This wind stress curl response pattern was consistent with the response patterns obtained from two additional experiments, that is, the stand-alone CAM2 and the CAM2-ocean mixed layer model experiments. Collectively, these results suggest that the North Pacific decadal variability in CCSM2 is a midlatitude coupled ocean-atmosphere mode with a weak ocean to atmosphere feedback as proposed by the theory of Neelin and Weng (1999).

The oceanic processes involved in CCSM2's North Pacific decadal variability, from the wind stress curl forcing to the decadal SST anomalies in the Kuroshio Extension and even the damping by the surface heat flux, are consistent with the processes involved in the 1976/77 PDO shift as found by observational and numerical modeling studies. The atmospheric response to the decadal SST anomalies still requires further investigation and better understanding, partly because of diverse results from previous atmospheric general circulation model studies and also because of the challenging task of examining the atmospheric response from observations or fully coupled model integrations.

Acknowledgments. We are very grateful to Dr. C. Cassou for the CAM2-ocean mixed layer model and its control integration output. We also wish to acknowledge helpful discussions and technical support from many colleagues including M. Alexander, A. Capotondi, B. Qiu, A. Phillips, S. Yeager, and D. Shea and constructive reviews by Dr. A. Miller and two anonymous reviewers. The first author gratefully acknowledges financial support from NOAA's Office of Global Programs (grant to C. Deser) and the CCSM Project Office.

\section{REFERENCES}

Alexander, M. A., J. D. Scott, and C. Deser, 2000: Processes that influence sea surface temperature and ocean mixed layer depth variability in a coupled model. J. Geophys. Res., 105, $16823-16842$.

Cassou, C., C. Deser, and M. A. Alexander, 2007: Investigating the impact of reemerging sea surface temperature anomalies on the winter atmospheric circulation over the North Atlantic. J. Climate, in press.

Chelton, D. B., and M. G. Schlax, 1996: Global observations of oceanic Rossby waves. Science, 272, 234-238.

_—, R. A. deSzoeke, M. G. Schlax, K. El Naggar, and N. 
Siwertz, 1998: Geographical variability of the first baroclinic Rossby radius of deformation. J. Phys. Oceanogr., 28, 433460.

Czaja, A., and C. Frankignoul, 2002: Observed impact of Atlantic SST anomalies on the North Atlantic Oscillation. J. Climate, 15, 606-623.

Deser, C., and M. L. Blackmon, 1995: On the relationship between tropical and North Pacific sea surface temperature variations. J. Climate, 8, 1677-1680.

— M. A. Alexander, and M. S. Timlin, 1999: Evidence for a wind-driven intensification of the Kuroshio current extension from the 1970s to the 1980s. J. Climate, 12, 1697-1706.

—, A. Phillips, and J. W. Hurrell, 2004: Pacific interdecadal climate variability: Linkages between the Tropics and North Pacific during boreal winter since 1900. J. Climate, 17, 31093124.

Frankignoul, C., and E. Kestenare, 2002: The surface heat flux feedback. Part I: Estimates from observations in the Atlantic and the North Pacific. Climate Dyn., 19, 633-647.

Fu, L.-L., and D. B. Qiu, 2002: Low-frequency variability of the North Pacific Ocean: The role of boundary- and wind-driven baroclinic Rossby waves. J. Geophys. Res., 107, 3220, doi:10.1029/2001JC001131.

Jin, F. F., 1997: A theory of interdecadal climate variability of the North Pacific ocean-atmosphere system. J. Climate, 10, 18211835.

Kelly, K. A., 2004: The relationship between oceanic heat transport and surface fluxes in the western North Pacific: 19702000. J. Climate, 17, 573-588.

Kiehl, J. T., and P. R. Gent, 2004: The Community Climate System Model, version 2. J. Climate, 17, 3666-3682.

Kushnir, Y., W. A. Robinson, I. Blade, N. M. J. Hall, S. Peng, and R. Sutton, 2002: Atmospheric GCM response to extratropical SST anomalies: Synthesis and evaluation. J. Climate, 15, 2233-2256.

Latif, M., and T. P. Barnett, 1994: Causes of decadal climate variability over the North Pacific and North America. Science, 266, 634-637.

— , and — 1996: Decadal climate variability over the North Pacific and North America: Dynamics and predictability. $J$. Climate, 9, 2407-2423.

Levitus, S., R. Burgett, and T. P. Boyer, 1994: Salinity. Vol. 3, World Ocean Atlas 1994, NOAA Atlas NESDIS 3, 99 pp.

Liu, Z., 1999: Forced planetary wave response in a thermocline gyre. J. Phys. Oceanogr., 29, 1036-1055.

Mantua, N. J., S. R. Hare, Y. Zhang, J. M. Wallace, and R. C. Francis, 1997: A Pacific interdecadal climate oscillation with impacts on salmon production. Bull. Amer. Meteor. Soc., 78, 1069-1079.

Marshall, J., H. Johnson, and J. Goodman, 2001: A study of the interaction of the North Atlantic Oscillation with ocean circulation. J. Climate, 14, 1399-1421.

Miller, A. J., D. R. Cayan, T. P. Barnett, N. E. Graham, and J. M. Oberhuber, 1994: Interdecadal variability of the Pacific Ocean: Model response to observed heat flux and wind stress anomalies. Climate Dyn., 9, 287-302.

- - , and W. B. White, 1998: A westward-intensified decadal change in the North Pacific thermocline and gyre-scale circulation. J. Climate, 11, 3112-3127.
Nakamura, H., and A. S. Kazmin, 2003: Decadal changes in the North Pacific oceanic frontal zones as revealed in the ship and satellite observations. J. Geophys. Res., 108, 3078, doi:10.1029/1999JC000085.

_ G. Lin, and T. Yamagata, 1997: Decadal climate variability in the North Pacific during the recent decades. Bull. Amer. Meteor. Soc., 78, 2215-2225.

Neelin, J. D., and W. J. Weng, 1999: Analytical prototypes for ocean atmosphere interaction at midlatitudes. Part I: Coupled feedbacks as a sea surface temperature dependent stochastic process. J. Climate, 12, 697-721.

Newman, M., G. P. Compo, and M. A. Alexander, 2003: ENSOforced variability of the Pacific decadal oscillation. J. Climate, 16, 3853-3857.

Nonaka, M., H. Nakamura, Y. Tanimoto, T. Kagimoto, and H. Sasaki, 2006: Decadal variability in the Kuroshio-Oyashio Extension simulated in an eddy-resolving OGCM. J. Climate, 19, 1970-1988.

Park, S., C. Deser, and M. A. Alexander, 2005: Estimation of the surface heat flux response to sea surface temperature anomalies over the global oceans. J. Climate, 18, 4582-4599.

Pierce, D. W., T. P. Barnett, N. Schneider, R. Saravanan, D. Dommenget, and M. Latif, 2001: The role of ocean dynamics in producing decadal climate variability in the North Pacific. Climate Dyn., 18, 51-70.

Qiu, B., 2002: Large-scale variability in the midlatitude subtropical and subpolar North Pacific Ocean: Observations and causes. J. Phys. Oceanogr., 32, 353-375.

_ 2003: Kuroshio Extension variability and forcing of the Pacific decadal oscillations: Responses and potential feedback. J. Phys. Oceanogr., 33, 2465-2482.

Saravanan, R., and J. C. McWilliams, 1998: Advective oceanatmosphere interaction: An analytical stochastic model with implications for decadal variability. J. Climate, 11, 165-188.

Schneider, N., and B. D. Cornuelle, 2005: The forcing of the Pacific decadal oscillation. J. Climate, 18, 4355-4373.

- A. J. Miller, and D. W. Pierce, 2002: Anatomy of North Pacific decadal variability. J. Climate, 15, 586-605.

Seager, R., Y. Kushnir, N. H. Naik, M. A. Cane, and J. Miller, 2001: Wind-driven shifts in the latitude of the KuroshioOyashio Extension and generation of SST anomalies on decadal timescales. J. Climate, 14, 4249-4265.

Smith, R. D., J. K. Dukowicz, and R. C. Malone, 1992: Parallel ocean general circulation modeling. Physica D, 60, 38-61.

Steele, M., R. Morley, and W. Ermold, 2001: PHC: A global ocean hydrography with a high-quality Arctic Ocean. J. Climate, 14, 2079-2087.

Taguchi, B., S.-P. Xie, H. Mitsudera, and A. Kubokawa, 2005: Response of the Kuroshio Extension to Rossby waves associated with the 1970s climate regime shift in a high-resolution ocean model. J. Climate, 18, 2979-2995.

Tanimoto, Y., H. Nakamura, T. Kagimoto, and S. Yamane, 2003: An active role of extratropical sea surface temperature anomalies in determining anomalous turbulent heat flux. $J$. Geophys. Res., 108, 3004, doi:10.1029/2002JC001750.

Trenberth, K., and J. W. Hurrell, 1994: Decadal atmosphereocean variations in the Pacific. Climate Dyn., 9, 303-319.

Xie, S.-P., T. Kunitani, A. Kubokawa, M. Nonaka, and S. Hosoda, 2000: Interdecadal thermocline variability in the North $\mathrm{Pa}$ cific for 1958-97: A GCM simulation. J. Phys. Oceanogr., 30, 2798-2813. 